\title{
Revisión de tendencias, innovaciones y buenas prácticas en el ámbito de los servicios sociales
}

\section{SIIS Centro de Documentación y Estudios, Fundación Eguía-Careaga}

estudios@siis.net

Artikulu honetan, oro har, gizarte-zerbitzuen eta, bereziki, gizarteratzeko zerbitzuen esparruan garatzen ari diren joera eta berrikuntza nagusiak errepasatzen dira, batez ere Europar Batasuneko herrialdeetan. Horretarako, oso modu orokorrean, berritzailetzat jo daitezkeen dozena bat ikuspegi edo eredu deskribatzen dira, eta, labur-labur, ikuspegi horiekin lotutako edo ikuspegi horietan oinarritutako zenbait esperientzia zehatz azaltzen dira. Azken atalean, deskribatutako ikuspegi eta esperientziak partekatzen dituzten ezaugarri komunak ere aipatzen dira. Metodologiaren ikuspuntutik, testua SIIS Dokumentazio eta Ikerketa Zentroaren gizartepolitikei buruzko bibliografia-fondoan jasotako literaturaren berrikuspenean oinarritzen da.

\section{GAKO-HITZAK:}

Gizarte-zerbitzuak, ekintza komunitarioa, joerak, berrikuntzak, pobrezia, autodeterminazioa, prebentzioa.
Este artículo repasa algunas de las principales tendencias e innovaciones que se están desarrollando en el ámbito de los servicios sociales en general, y de los servicios para la inclusión social en particular, fundamentalmente en los países de la Unión Europea. Para ello se describen de forma muy genérica una docena de enfoques o modelos que cabe considerar innovadores $y$, muy brevemente, se señalan algunas experiencias concretas relacionadas o basadas en tales enfoques. También se señalan, en el último apartado, las características comunes que comparten los enfoques y experiencias descritos. Desde el punto de vista metodológico, el texto se basa en una revisión de la literatura recogida en la base bibliográfica sobre políticas sociales del SIIS Centro de Documentación y Estudios.

\section{PALABRAs ClaVe:}

Servicios sociales, acción comunitaria, tendencias, innovaciones, pobreza, autodeterminación, prevención. 


\section{Introducción}

Este artículo repasa algunas de las principales tendencias e innovaciones que se están desarrollando en el ámbito de los servicios sociales en general, y de los servicios para la inclusión social en particular, fundamentalmente en los países de la Unión Europea. Para ello se describen de forma muy genérica una docena de enfoques o modelos que cabe considerar innovadores y, muy brevemente, se señalan algunas experiencias concretas relacionadas o basadas en tales enfoques. También se señalan, en el último apartado, las características comunes que comparten los enfoques y experiencias descritos.

A la hora de interpretar el contenido del texto, es necesario tener en cuenta las dificultades que supone describir e identificar tendencias, innovaciones o buenas prácticas en el ámbito de los servicios sociales. Por una parte, debe decirse que no todos los enfoques y experiencias que se recogen pueden considerarse estrictamente innovadores (en ocasiones, ni siquiera novedosos), aunque sí se puede afirmar que existe en la actualidad un renovado interés por todos ellos o que suponen una ruptura con las fórmulas tradicionales de organización y prestación de servicios. Por otra parte, no todos los enfoques o experiencias que se señalan han sido suficientemente evaluados y no puede por tanto hablarse en todos los casos de evidencias en relación con su efectividad. La fidelidad de las diversas experiencias a un modelo o patrón determinado suele ser además reducida y, en general, las experiencias prácticas solo responden en parte a modelos o enfoques claramente establecidos. Este texto no tiene por objeto, en cualquier caso, realizar una revisión sistemática respecto a la efectividad de estos programas, ni describirlos en profundidad, sino identificar algunas tendencias de innovación y de cambio en el ámbito de los servicios sociales, y analizar los elementos comunes que subyacen a todas ellas.

También debe señalarse la dificultad para clasificar y ordenar estos enfoques y experiencias, que en ocasiones están claramente relacionados entre sí, comparten elementos centrales y son por tanto difíciles de delimitar. En cualquier caso, el texto se articula en torno a una docena de enfoques que resultan suficientemente diferenciados y singulares. Otra de las dificultades de este tipo de revisiones se debe al diferente alcance de los enfoques identificados: algunos implican mejoras 0 adaptaciones de lo que ya se viene haciendo, mientras que en otros casos se intenta modificar de raíz el modelo anterior de prestación de servicios. En cualquier caso, en esta revisión se ha intentado hacer referencia a enfoques de suficiente alcance o calado, y detallar cómo se han materializado en experiencias concretas.

No hay duda, por otra parte, de que existen otras tendencias e innovaciones de gran interés que no se han recogido en el texto, tanto por motivos de espacio como por su menor difusión en las fuentes de información consultadas. Por último, cabe señalar que si bien la práctica totalidad de las experiencias reseñadas están actualmente en vigor, también se hace referencia por su interés a alguna experiencia ya finalizada.

Desde el punto de vista metodológico, el texto se basa en una revisión de la literatura recogida en la base bibliográfica sobre políticas sociales del SIIS Centro de Documentación y Estudios, y actualiza revisiones similares realizadas por este centro para el Observatorio de la Realidad Social del Gobierno de Navarra (SIIS, 2016), para el Departamento de Empleo y Políticas Sociales del Gobierno Vasco (SIIS, 2017b) o para Emaús Fundación Social en el marco del proyecto Inclúe (Blanco et al., 2015). Algunos de los textos están adaptados, por otra parte, de diversas entradas publicadas por el equipo del SIIS en el blog de ese centro ${ }^{1}$.

\section{La comunidad al rescate: activación comunitaria y voluntariado de proximidad}

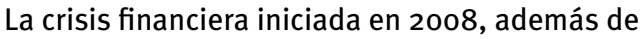
las diversas transformaciones sociales que se han venido sucediendo en las estructuras familiares y el mercado laboral, junto con la existencia de nuevos riesgos sociales, han generado un contexto de incertidumbre en el que se cuestiona la capacidad del Estado de Bienestar para hacer frente a esta situación. La necesidad de buscar fórmulas de intervención social más eficientes y efectivas hace de la comunidad una alternativa de gran relevancia para reforzar y cubrir así aquellos espacios a los que el Estado de Bienestar no puede llegar (Arrieta et al., 2018).

Efectivamente, en los últimos años se está produciendo un redescubrimiento de las iniciativas autogestionadas y de la importancia de los vínculos comunitarios y relacionales, de base territorial, en el desarrollo de las políticas sociales. Esto se debe tanto a un cierto agotamiento de los servicios públicos convencionales y a la creciente insuficiencia de las políticas sociales para dar respuesta a necesidades cada vez más complejas, como a la demanda de modelos más flexibles y más ágiles, con mayores posibilidades de responder a la diversidad de expectativas, exigencias y necesidades de la población. Si bien es cierto que el fomento de estas iniciativas puede entenderse como una desvinculación respecto a la prestación de servicios sociales por parte de las Administraciones Públicas, también puede entenderse como un complemento y refuerzo de éstos, de cara precisamente a garantizar su sostenibilidad (SIIS, 2017a). La apuesta por este tipo de enfoques ha sido en ocasiones impulsada por la propia administración, como en el caso de la big society británica o la sociedad participativa 
neerlandesa, mientras que en otras ocasiones - caso del movimiento de los comunes o del secondo welfare italiano- parte fundamentalmente de la sociedad civil.

Este resurgimiento de las iniciativas solidarias se caracteriza por dos elementos complementarios: el impulso a las fórmulas y redes de autoorganización comunitaria mediante el fomento de la solidaridad local y de proximidad, de una parte, y el recurso a nuevas fórmulas de implicación en la acción voluntaria -entre las que destaca el voluntariado de persona a persona, como los programas de mentoría y padrinazgo-, de otra. Es también evidente la relación entre estas experiencias y el auge de nuevos enfoques basados en el municipalismo, el derecho a la ciudad y la producción del bien común ${ }^{2}$, así como con los basados en la cocreación de servicios y la implicación de las personas usuarias y del conjunto de la ciudadanía en su diseño (Zuñiga et al., 2019).

Las experiencias desarrolladas en este ámbito, tanto en Euskadi como en otras comunidades autónomas o países de nuestro entorno, son numerosas. Cabe citar entre ellas programas de mentoría como el proyecto Izeba 3 , basado en los modelos de mentoría social $^{4}$, el programa LKaleak $^{5}$ desarrollado en el barrio donostiarra de Egia -que apuesta por la cocreación para el diseño de servicios comunitarios a las personas mayores- y el resto de los programas incluidos en la iniciativa Bizilagun Sareak ${ }^{6}$, impulsada por la Diputación Foral de Gipuzkoa en el marco del programa Etorkizuna Eraikiz. En otros ámbitos territoriales, cabe destacar iniciativas como La Escalera ${ }^{7}$, en Madrid, Radars ${ }^{8}$ en Barcelona, o las redes de vecindad solidaria desarrolladas en Francia ${ }^{9}$, Canadá ${ }^{10}$ y otros países.

2 Para Gomá (2019: 35), "hoy, en pleno siglo XXI, forjar un modelo de ciudadanía social en torno al bienestar de proximidad, la justicia espacial y la transición ecológica - frente a las desigualdades, la gentrificación y el cambio climático- nos conduce hacia un nuevo reto operativo/relacional: superar tanto el monopolismo burocrático como la 'nueva gestión pública' y reformular la gobernanza participativa en términos de construcción del común. Se trata de crear una esfera compartida de producción de ciudadanía y democracia activa, a partir de la confluencia entre lo institucional y lo comunitario: espacios donde forjar lo común desde estrategias múltiples (territorializar la gobernanza, coproducir políticas sociales y urbanas, impulsar la acción comunitaria, abrir la gestión a la ciudadanía y apoyar la innovación social)".

3 El proyecto Izeba (〈https://youtu.be/L5AtFBVqX30〉) se configura como una red de familias o personas (hogares) que aceptan actuar como tíos/as acogedores/as de personas menores tuteladas, para realizar un trabajo de acompañamiento y contribuir a mejorar su calidad de vida.

${ }^{4}$ Existe una coordinadora estatal de mentoría social («http:// www.mentoriasocial.org ), que agrupa 14 proyectos de 11 entidades en Cataluña, Euskal Herria y Madrid.

${ }^{5}$ http://lkaleak.eus/es/.

6 https://www.gipuzkoa.eus/es/web/etorkizunaeraikiz/proyectos/bizilagun-sarea/.

7 http://www.proyectolaescalera.org.

8 https://ajuntament.barcelona.cat/acciocomunitaria/ca/noticia/10 -anys-de-projecte-radars_607187.

9 https://voisinssolidaires.fr.

${ }^{10} \mathrm{http}: / /$ voisinssolidaires.ca/a-propos/\#vision.
3. La fuerza de los territorios: los activos comunitarios, las ciudades amigables y el bienestar de proximidad

El papel de los territorios y las comunidades de base local es esencial en el enfoque de la activación comunitaria que acaba de señalarse. Estrechamente relacionado por tanto con ese enfoque, y a partir del paradigma de los activos en salud desarrollado en el ámbito de la salud pública ${ }^{11}$ (Cofiño et al., 2016), también en el ámbito de los servicios sociales se viene trabajando desde la perspectiva de los activos comunitarios y territoriales (asset based places, en inglés).

Este enfoque responde claramente al protagonismo alcanzado por conceptos como el derecho a la ciudad y al desarrollo de una nueva agenda urbana, en la que el municipalismo adopta un papel relevante. Como explica Gomà (2019: 2), “tras la gran recesión, las metrópolis emergen como espacios clave en la configuración de la sociedad líquida y de la nueva economía global. Los gobiernos locales aparecen con fuerza como agentes de poder político. La (re) construcción de los derechos sociales en el siglo XXI incorpora una dimensión cotidiana y espacial inédita. El derecho a la ciudad, allí donde se cruzan las agendas social y urbana del nuevo municipalismo, surge como componente básico del estado de bienestar" ${ }^{12}$. En ese marco, las comunidades locales - las ciudades, los pueblos y los barrios- emergen como el escenario privilegiado para el desarrollo de programas que implican a todos los agentes públicos, privados y comunitarios- que operan en el territorio.

Aunque presenta también otros componentes de interés, el modelo Buurtzorg ${ }^{13}$, desarrollado primero en los Países Bajos y después en otros países de Europa, se basa en esa idea del bienestar de

\footnotetext{
${ }^{11}$ De acuerdo con Morgan y Hernán (2013: 78), “el enfoque de activos en las políticas de salud pública, investigación y práctica, pretende apoyar a los individuos, las comunidades y las organizaciones para la adquisición de habilidades y competencias que maximicen las oportunidades de salud y bienestar. Este enfoque se caracteriza por dos ideas principales. En primer lugar, se centra en las soluciones y no en los problemas. Es decir, pretende fomentar que los programas de salud creen las condiciones de salud que potencien las capacidades y habilidades de los individuos y los colectivos. De esta manera, el modelo de activos promociona que las poblaciones sean menos dependientes de los servicios sociales y de salud, de modo que ante el clima económico imperante, los recursos limitados de los que disponemos sean destinados a aquellos que más lo necesitan. En segundo lugar, posiciona a los individuos en el eje central del proceso de desarrollo de la salud. El éxito y la sostenibilidad de un programa de salud están en directa relación con el grado de implicación de la población local a la cual se dirige el mismo".

${ }_{12}$ Según Gomà (2019: 18), “las vulnerabilidades conectadas a la esfera socioeconómica del cambio de época convocan a forjar una arquitectura más espacial del estado de bienestar; a (re)construir la ciudadanía social del siglo XXI desde la centralidad de la agenda urbana. En síntesis, la dimensión socioespacial adquiere centralidad en las esferas clave del cambio de época; se dibuja un cruce histórico tal vez inédito entre cambio social y cuestión urbana. Es en este escenario que el derecho a la ciudad (la suma de bienestar de proximidad y agenda urbana) puede tender a ganar fuerza en el estado de bienestar de las próximas décadas".

${ }^{13}$ https://www.buurtzorg.com.
} 
proximidad y de los activos comunitarios. El modelo Burtzoorg está basado en la idea de la enfermería comunitaria y se basa en la creación de equipos muy reducidos de trabajadores o trabajadoras comunitarias que atienden de forma autogestionada a las personas con fragilidad o dependencia de territorios muy reducidos, lo que implica un nivel de personalización y proximidad muy elevado. Cada equipo, formado por una docena de trabajadores o trabajadoras autogestionados, atiende a entre cuarenta y cincuenta personas usuarias, residentes en ámbitos territoriales no superiores a los 10.000 habitantes. Los resultados de las evaluaciones realizadas parecen confirmar el éxito del modelo, tanto desde el punto de vista de las personas profesionales como de las personas usuarias (Drennan et al., 2018).

Las superilles o "supermanzanas sociales" desarrolladas en Barcelona suponen una de las aplicaciones más claras y avanzadas de este modelo de atención comunitaria de base territorial en nuestro entorno. De acuerdo con Torrens (2018), la supermanzana social traslada la idea de la tribu como responsable de la educación infantil, popularizada por Tonucci, a la idea de la tribu como responsable de los cuidados a las personas mayores. En términos prácticos, el proyecto piloto de las superilles sociales barcelonesas, basadas en las supermanzanas urbanísticas desarrolladas en la ciudad ${ }^{14}$, se plantea como equipos de atención domiciliaria que atienden a las personas que residen en una supermanzana, lo que permite la continuidad, la proximidad y la personalización de la atención. En una primera fase de despliegue (Ayuntamiento de Barcelona, 2017), en cada supermanzana se atiende a entre cuarenta y sesenta personas usuarias del Servicio de Ayuda a Domicilio, con equipos de hasta doce profesionales, que pueden trabajar a jornada completa planificando, personalizando y flexibilizando la atención a las personas usuarias.

La importancia de los factores territoriales se ve también reflejada en los muy diversos proyectos que se vienen realizando en nuestro entorno en relación con el concepto de amigabilidad urbana. Particularmente relacionados con la atención a las personas mayores y a la infancia, este concepto se basa en la adaptación de los entornos urbanos a las necesidades particulares de determinados colectivos, como las personas mayores o la infancia. Desde ese punto de vista, cabe citar la iniciativa de Euskadi Lagunkoia ${ }^{15}$, impulsada por el Departamento de Empleo y Políticas Sociales del Gobierno Vasco en colaboración con la Fundación Matia, o el programa

${ }^{14} \mathrm{http}: / /$ ajuntament.barcelona.cat/superilles/es/.

15 Euskadi Lagunkoia (〈https://euskadilagunkoia.net〉) es una iniciativa promovida por el Gobierno Vasco y puesta en marcha por la Fundación Matia que tiene como objetivo incentivar la participación de las personas mayores y de la ciudadanía en general para la mejora de barrios y entornos en los municipios de Euskadi, con el fin de que podamos seguir haciendo nuestra vida a medida que envejecemos. Se basa en la iniciativa Age-friendly Environments Programme promovida por la OMS. de Ciudades Amigas de la Infancia ${ }^{16}$, impulsado por Unicef y en el que participan, entre otros, el Ayuntamiento de Vitoria-Gasteiz.

\section{4. 'Cash for care': el apoyo autodirigido, la asistencia personal y los presupuestos personales}

La autodeterminación y el control por parte de las personas usuarias está en la base del desarrollo en diversos países de prestaciones económicas que facilitan el acceso a los servicios de cuidado. Planteados en cierto modo como cheques servicio, el objetivo de estos modelos no es en cualquier caso el de liberalizar el acceso a los cuidados -aunque en alguna situación pudiera serlo-, sino el de otorgar a las personas usuarias una mayor capacidad de elección y control en relación con los servicios -generalmente, aunque no solo, de cuidado y asistencia personal-que pudieran requerir.

En relación con este tipo de enfoques, un estudio del SIIS realizado en 2011 sobre prestaciones económicas y otras fórmulas de asignación económica individual en los sistemas de atención a la dependencia (SIIS, 2011), indicaba que todas estas prestaciones tienen en común que: sus beneficiarios directos son las personas usuarias, es decir, las personas que necesitan apoyos para las actividades de la vida diaria; y se otorgan para que la persona usuaria se encargue de adquirir o de compensar con ellas la atención que requiere, prestada, según los casos, por entidades de servicios, cuidadores profesionales autónomos o cuidadores informales. Se articulan como alternativas a la prestación de servicios en especie, es decir, ofrecen la posibilidad de sustituir la atención diseñada, organizada y prestada - directa o indirectamente-desde los servicios sociales públicos, por la atención diseñada, organizada y contratada por la propia persona usuaria, dotándola para ello de medios económicos que puede utilizar para contratar los apoyos requeridos, prestados por las entidades o los cuidadores de su elección.

Para hacerlo, los sistemas vigentes optan unas veces por utilizar prestaciones económicas en sentido estricto, es decir cuantías concedidas en metálico a la persona beneficiaria, $y$ otras veces por utilizar una asignación económica individual consistente en poner a disposición de la persona un presupuesto o fondo personal o individual, expresado en horas de apoyo o en cuantía económica. En el ámbito internacional, este conjunto de medidas obedece a la filosofía de la "atención dirigida por la persona usuaria", integrada en los sistemas de servicios sociales bajo diferentes denominaciones: unas

${ }^{16}$ Una Ciudad Amiga de la Infancia («https://ciudadesamigas. org) es cualquier ciudad, pueblo, comunidad o sistema de gobierno local comprometido con el cumplimiento de los derechos de las niñas, los niños y los adolescentes de acuerdo con la Convención sobre los Derechos del Niño. 
referidas a los instrumentos que articulan sus variantes -individual funding, personal budget, direct payment-; otras, con mayor fuerza expresiva, referidas directamente a ese protagonismo de la persona usuaria - consumer-directed care, selfdirected support, self-managed care-.

De acuerdo con ese informe, la extensión a partir de las décadas de los ochenta y los noventa de este tipo de modelos responde a una crisis tanto organizativa - determinada por la rigidez y los imperativos administrativos asociados a la prestación pública de servicios-, como financiera - centrada en la dificultad de sostener económicamente la prestación pública de servicios sociales ante la creciente demanda de servicios-. En ese contexto, el problema esencial que las nuevas políticas debían resolver era ampliar la oferta de servicios sin que eso se tradujera en una presión excesiva sobre los costes. Esta necesidad entraba en contradicción con los límites presupuestarios y fiscales, pero también con la inercia y lo que se percibía como una excesiva burocratización de los modelos vigentes, de modo que se vio necesario encontrar nuevas fórmulas organizativas que hicieran viable la expansión del sistema combinando diversos objetivos:

- reducir los gastos de funcionamiento mediante una utilización más eficiente, eficaz y racional de los recursos disponibles;

- incrementar los recursos económicos destinados a la prestación de servicios sociales personales para garantizar su capacidad de respuesta a las previsiones poblacionales;

- regular el acceso al sistema público de servicios sociales para dar contenido al derecho de las personas en situación de necesidad y evitar la discrecionalidad hasta entonces vigente; $y$

- diversificar la gama de servicios disponibles para favorecer el paso de un modelo marcadamente institucional a un modelo comunitario y para reforzar la existencia de soluciones de carácter preventivo que retrasasen o evitasen el recurso a soluciones más costosas.

No debe olvidarse por otra parte que, simultáneamente a la crisis administrativa y económica del modelo, se estaba produciendo un movimiento de fondo en la población atendida, a resultas del cual se fue imponiendo una corriente que, desde un enfoque progresista y de reconocimiento de derechos, pretendía establecer un sistema de atención centrado en la persona usuaria y en la promoción de su autonomía, de su libre elección y de su autodeterminación.

En ese sentido, puede decirse que las demandas y deseos manifestados por las personas usuarias de contar con servicios menos estandarizados, más ajustados a las necesidades individuales y más variados, que les permitieran elegir las opciones más adecuadas y participar activamente en el diseño de su paquete de apoyos, estaba en sintonía con las necesidades constatadas por la propia Administración en términos de ampliación y diversificación de la red y en términos de eficiencia y agilidad en la organización y el funcionamiento del sistema. Así es como los valores de personalización de la atención, de empoderamiento, de autodeterminación y de derecho de elección se integraron en el discurso público de los diferentes modelos de servicios sociales y cómo se impuso, en todos ellos, la necesidad de ajustar mejor la oferta de servicios y el modelo de atención a las necesidades individuales y, en lo posible, a las preferencias de la persona usuaria. Se pasaba así del paradigma de la atención ofrecida en función de la red de servicios, al paradigma de la atención ofrecida en función de las necesidades individuales. Esto ocurrió, con mayor o menor énfasis, en todos los sistemas:

- Para los sistemas de corte liberal, este reforzamiento de la dimensión individual encajaba muy bien con los planteamientos de mercado, en los que este se caracteriza por ofrecer alternativas diversas y es el consumidor quien elige la fórmula que más le conviene, que mejor responde a sus necesidades y preferencias.

- Para los sistemas de corte socialdemócrata, esta nueva concepción era una vía de modernización de los sistemas, una oportunidad de mejorar la connivencia entre la Administración y la colectividad y, en última instancia, de garantizar la pervivencia de un sistema de acción colectiva. En su marco, la modernización se presenta como una respuesta necesaria a un público cada vez más demandante y a un mundo que cambia a un ritmo sin precedentes.

Los ejemplos de este tipo de enfoques son muchos. Cabe señalar como principal novedad el modelo de self-directed support (traducible como "apoyo autodirigido") desarrollado desde 2014 en Escocia ${ }^{17}$. En aquel país, con la entrada en vigor en 2014 de la Social Care (Self-directed Support) Act, el grueso de los servicios sociales para personas adultas y mayores se presta mediante este sistema, según el cual las autoridades locales están obligadas a ofrecer a las personas con derecho a la recepción de servicios cuatro opciones diferentes: una prestación económica (direct payment) que se abona a la persona usuaria y que ella administra para el pago de los servicios comunitarios o domiciliarios que precisa; un presupuesto o fondo individual para la financiación de los servicios que se destina a una entidad proveedora elegida por la persona usuaria; un servicio de atención directa; o una combinación de las tres opciones. El pago directo no incluye el acceso a servicios de atención residencial, aunque sí a servicios de vivienda tutelada, mientras que los otros tres sí. Se calcula que en 2017 el $70 \%$ de los usuarios de los servicios sociales pudieron elegir entre alguna de las cuatro opciones disponibles, con un gasto cercano a los 600 millones de libras. El $83 \%$

${ }^{17}$ https://youtu.be/-ErFT466CgU. 
de las personas usuarias optaron en cualquier caso por la percepción de un servicio de atención prestado directamente por las instituciones.

También cabe considerar referentes en este enfoque la Prestation de Compensation du Handicap $(\mathrm{PCH})$ y la Allocation Personalisé d'Autonomie (APA) en Francia, el nuevo Personal Independence Payment (PIP) en el Reino Unido, las prestaciones en el marco del seguro de dependencia alemán, la Indemnitá di Accompagnamento italiana, con una ya larga andadura, o los presupuestos personales neerlandeses, actualmente en proceso de residualización. De acuerdo con un reciente estudio (Ranci et al., 2019) en el que se comparan las principales características de seis de estas prestaciones, los importes medios mensuales oscilan entre los 311 euros de España y los 618 de Francia, con tasas de cobertura que varían entre el $0,83 \%$ de la población en España y el 7,9\% en el Reino Unido. El gasto por habitante oscila a su vez entre los 14 euros por cada 100 habitantes en Francia y los 40 en Reino Unido. Las evaluaciones realizadas ponen de manifiesto, por otra parte, la tensión a la que estos modelos se enfrentan a la hora de combinar cobertura y generosidad, así como el papel que han jugado a la hora de fomentar bien el cuidado familiar, bien el cuidado profesional de baja remuneración, o ambos (Da Roit y Le Biham, 2019).

También en nuestro marco debe hacerse referencia al desarrollo del modelo de asistencia personal en Gipuzkoa (Benedicto, 2013) o a la nueva regulación del modelo de Prestación Económica de Asistencia Personal (PEAP) aprobada por el Gobierno de Navarra que establece cuantías de entre 560 y 1.600 euros mensuales, abre el acceso a esta prestación - de forma no garantizada- a las personas con discapacidad y sin valoración de dependencia (siempre que tengan un grado de discapacidad superior al $65 \%$ ) y extiende el tipo de actividades que puede realizar el o la asistente personal contratada mediante esta prestación $\mathrm{n}^{18}$.

\section{Desinstitucionalización, atención centrada en la persona y nuevas arquitecturas de cuidado}

Estrechamente relacionado con otros enfoques, como la planificación centrada en la persona o el modelo

${ }^{18}$ De acuerdo con la Orden Foral 224/2019, de 31 de mayo, del Consejero de Derechos Sociales, por la que se regula la prestación económica para asistencia personal de las personas que tengan reconocida una situación de dependencia o discapacidad, con carácter general, en función de las necesidades de las personas usuarias, las funciones de el o la asistente personal podrán ser las siguientes: apoyo en materia de higiene, alimentación, mantenimiento de la salud y autocuidados; apoyo en tareas domésticas; apoyo en desplazamientos; apoyo en la comunicación; apoyo en el contexto laboral; apoyo a la formación profesional; apoyo a la asistencia a la enseñanza superior y de investigación; apoyo en contextos culturales, de ocio y deporte; apoyo en actividades de mejora de la empleabilidad; apoyo a la participación comunitaria y ciudadanía; apoyo en el desarrollo de actividades especiales mutuamente acordadas. de apoyos, no cabe duda de que la atención centrada en la persona es uno de los enfoques o modelos que en mayor medida está modificando la forma de organizar la prestación de servicios sociales a las personas mayores y con discapacidad. También en el ámbito de la atención a las personas en situación de exclusión social se están desarrollando enfoques que parten de la filosofía de la atención centrada en la persona (Zalakain, 2017) y que enfatizan elementos como la desinstitucionalización, la individualización o la autodeterminación de las personas usuarias.

De acuerdo con Martínez, Díaz-Veiga, Sancho y Rodríguez, "el modelo de atención centrada en la persona consiste en el desarrollo de diversas medidas en el entorno físico, social y organizativo, con el fin de promover la calidad de vida de las personas que necesitan cuidados. Es una forma de entender la relación asistencial, donde la persona es protagonista activa, donde el entorno y la organización se convierten en apoyos para desarrollar los proyectos de vida y el bienestar de las personas" (Martínez et al., 2014: 7). La extensión del modelo de atención centrado en la persona se ha equiparado, en ese sentido, a un profundo cambio en la cultura asistencial y organizacional de los servicios de atención a las personas mayores y, globalmente, del conjunto de los servicios sociales. Simplificando, quizás en exceso, puede señalarse que el cambio cultural o de paradigma que representa el modelo de atención centrada en la persona (ACP) se asienta sobre dos ejes diferentes, aunque estrechamente interrelacionados:

- por una parte, el propio modelo de atención e intervención, que se traduce en un cambio drástico en cuanto a los roles y figuras profesionales, las ratios de atención, las actividades realizadas y, en términos generales, la filosofía de la atención;

- por otra, los cambios en la configuración física de los centros y en la determinación de los aspectos arquitectónicos y ambientales en los que se prestan los cuidados, que han dado pie a lo que algunas autoras denominan "arquitecturas del cuidado" (Mogollón y Fernández, 2016) ${ }^{19}$. En ese sentido, de acuerdo con Martínez Rodríguez (2016), al existir una clara influencia del ambiente físico en la conducta y en el bienestar de las personas mayores en situación de dependencia, el componente ambiental se muestra como un componente clave a tener muy en cuenta en el diseño y aplicación de modelos orientados desde la ACP.

Existe efectivamente una creciente evidencia científica en relación con la influencia del entorno

19 Para estas autoras, más allá de las infraestructuras físicas “duras", una propuesta teórica de arquitecturas del cuidado incluiría txokos o elkarteak de cuidados, portales cuidadanos, equipamientos y espacios públicos, viviendas compartidas, colectivas, comunitarias y colaborativas, cuadrillas, centros de día, bingos, cafeterías o fiestas patronales. 
físico en la calidad de vida de las personas mayores que viven en un centro residencial. La más reciente y exhaustiva revisión de la literatura publicada en los últimos años con respecto a esta cuestión (Joseph et al., 2016) indica con claridad que la mejora del entorno físico en el que viven las personas se considera, cada vez más, como uno de los factores clave en la mejora de la calidad de vida de las personas.

En el caso concreto de las demencias, está demostrado que el entorno físico es un factor crítico en el contexto terapéutico de los pacientes. En las tres últimas décadas, la literatura especializada ha demostrado la relación existente entre el diseño de espacios poco acogedores y agradables y el incremento de ciertos síntomas en los pacientes con demencia, como son la desorientación espacial, la ansiedad, la agitación y el retraimiento o aislamiento social. Por el contrario, el cuidado del entorno y el diseño de espacios físicos acogedores han demostrado ser factores positivos para la evolución de estos pacientes, al dar lugar a una reducción de los síntomas de ansiedad y agitación, potenciar un incremento de sus relaciones sociales y favorecer una mayor autonomía de estos pacientes para realizar las actividades de la vida diaria (Chaudhury et al., 2014).

La reflexión anterior es de aplicación tanto a las personas que residen en sus domicilios - para quienes la creación de ciudades y viviendas accesibles y amigables resulta indispensable-, como para las personas que residen en centros de alojamiento. En el caso de estas últimas -y particularmente en el caso de las personas con demencias u otros trastornos cognitivos-, el diseño de entornos terapéuticos se incluye cada vez en mayor medida dentro de los enfoques no farmacológicos para minimizar el efecto que produce el deterioro físico y cognitivo asociado a la edad en las capacidades de las personas: un entorno diseñado específicamente para personas con demencia puede fortalecer y estimular la utilización de las capacidades que se mantienen, ralentizar su pérdida, e ir supliendo aquellas que se van perdiendo. Un entorno pensado, diseñado y ejecutado adecuadamente para dar respuesta a las necesidades específicas de las personas que lo habitan o utilizan puede llegar a ser una herramienta muy útil para aminorar síntomas asociados a las demencias como la deambulación, desorientación, agitación, retraimiento social y otros.

Las revisiones de la literatura realizadas en relación con la influencia del entorno físico en la calidad de vida de las personas mayores -y, más concretamente, de las personas residencializadasarrojan resultados concluyentes: la forma en la que se articula el espacio interno y externo de los centros residenciales, junto con la relación de estos con el entorno, juega un papel esencial en numerosos aspectos relacionados con la calidad de vida de las personas mayores residencializadas, así como en las condiciones de trabajo de los profesionales y la satisfacción de las personas cuidadoras (Huisman et al., 2012; Joseph et al., 2016; Zimmerman et al., 2013; Bradshaw et al., 2012). En efecto, como señalan Joseph et al. (2016), el entorno físico es un componente integral de la atención basada en la persona que se presta en los centros residenciales y su diseño arquitectónico resulta crucial para promover la salud, el bienestar y la personalización de la atención de la población residente.

Estos enfoques se complementan con la evidencia disponible en relación con la importancia de la desinstitucionalización de la atención a las personas con dependencia, discapacidad o enfermedad mental, y con el impulso a la provisión de servicios de alojamiento en entornos comunitarios (Agencia de los Derechos Fundamentales de la Unión Europea, 2018; Tatlow-Golden et al., 2014; Chowdhury y Benson, 2011; Dirección General de Empleo, Asuntos Sociales e Igualdad de Oportunidades, Comisión Europe, 2011; Mansell et al., 2011).

Las experiencias innovadoras en lo que se refiere al diseño arquitectónico y ambiental de los centros para personas mayores y con discapacidad son cada vez más habituales. Cabe hacer referencia en ese sentido al modelo Green House ${ }^{20}$ desarrollado en Estados Unidos y que cuenta en la actualidad con más de 214 viviendas en funcionamiento en 30 de los 50 estados de Estados Unidos. Una vivienda Green House es una vivienda independiente para 10-12 personas mayores, con diferentes niveles de dependencia. Suelen estar construidas con similares características a las de las viviendas del entorno. Se caracterizan por la promoción de una relación más estrecha entre cuidadores y residentes (con figuras profesionales como el shahbaz ${ }^{21}$ ), el vuelco absoluto a la organización institucional tradicional, el respeto a las preferencias individuales y la flexibilidad en las rutinas de funcionamiento, la articulación en torno a viviendas de 10-12 personas, con baño privado en cada habitación, integradas en la comunidad, la voluntad de reproducir un entorno hogareño, con cocina y comedor común y fácil acceso al exterior de la vivienda (Miller et al., 2016). Los estudios de evaluación de este modelo han puesto de manifiesto

\footnotetext{
${ }^{20}$ https://youtu.be/cDHZkVkndrl.

${ }^{21}$ Shahbaz significa "halcón del rey" en persa y simboliza la figura cercana de apoyo. En ese sentido, uno de los puntos fuertes y característicos de las green houses es el equipo profesional. Este se compone de un grupo de auxiliares de enfermería con formación adicional sobre los principios del modelo Green House. Estos profesionales, denominados shahbaz, se definen por su polivalencia: realizan diversas actividades de atención directa, pero también gestionan la vivienda - lavandería, cocina- y, fundamentalmente, son quienes mantienen una relación más estrecha con la persona residente. Estos shahbaz componen equipos de trabajo que aspiran a autogestionarse, por lo que se fomenta la mayor asunción posible de responsabilidad por parte de los shahbaz, que cuentan con el apoyo y asesoramiento de un guía. La polivalencia de los shahbazim permite dedicar más horas de atención en la vivienda estableciendo un contacto más estrecho con las personas residentes. Este aspecto se considera fundamental en la mejora de la calidad de vida y de la atención que se produce en las viviendas Green House. Los estudios muestran una mayor satisfacción laboral del personal, mayor permanencia en el puesto y cuatro veces más tiempo de relación con las personas mayores (entre 23 y 31 minutos al día por residente, con la misma ratio).
} 
una reducción de costes importante respecto a los modelos tradicionales, mejoras en la calidad de la atención (mayor tiempo de atención directa, mayor implicación con las personas mayores, menos estrés y menos úlceras) y mejora en la satisfacción de las familias y del personal (Zimmerman et al., 2016).

También cabe hacer referencia en Europa al modelo Hogeweyk ${ }^{22}$ desarrollado en los Países Bajos y en vías de extensión a otros países. Igualmente, merece una atención específica el modelo de cohousing o de viviendas colaborativas para personas mayores ${ }^{23}$ que viene implantándose en diversos países de nuestro entorno (Mogollón y Fernández, 2016: 28). De acuerdo con estas autoras, las viviendas colaborativas son "apartamentos privados completos que cuentan con espacios y/o servicios comunes compartidos por las personas residentes que están basadas en sistemas de organización interna horizontales que fomentan la colaboración interna para la consecución de los objetivos. Esto supone la existencia de una personalidad jurídica o formal para el colectivo, unos modos de gestión específica y con soberanía vecinal en la toma de decisiones. Además de estas características básicas, cada proyecto puede incluir un amplio abanico de otras características que son típicas en la mayoría de los casos pero que pueden estar presentes en algunos colectivos (propiedad común con cesión de uso, autogestión comunitaria de todas las labores, procesos participativos, diseño participativo y/o intencional, trabajos obligatorios, comidas comunitarias...). En algunos casos pueden llegar incluso a plantear objetivos ambiciosos como la economía compartida, la autogestión total de las necesidades o la reducción del impacto ecológico, siempre desde la proximidad en la residencia y las prácticas cotidianas para la construcción de realidades transformadoras".

En nuestro entorno más cercano, además del centro residencial previsto para el barrio donostiarra de Trintxerpe en el marco del proyecto Adinberri, cabe hacer referencia al proyecto de apartamentos con apoyo Etxegoki ${ }^{24}$ desarrollado por la Federación Coordinadora de Personas con Discapacidad Física y Orgánica de Bizkaia (Fekoor) o a los proyectos desarrollados por la Fundación Matia en el marco del proyecto Etxean Ondo en residencias ${ }^{25}$ (Díaz-Veiga et al., 2016; Sancho Castiello y Díaz Veiga, 2014; DíazVeiga et al., 2014).

\section{Baja exigencia, incondicionalidad y derecho a la vivienda: el programa Housing First}

Durante los últimos años ha ido adquiriendo cada vez mayor relevancia, en el debate técnico y social, el modelo Housing First ("vivienda primero", en inglés)

${ }^{22}$ https://youtu.be/YSZhrxOkBZI.

${ }^{23}$ https://youtu.be/t4GuToTRJ8s.

${ }^{24}$ https://youtu.be/hq3IVoaelgs.

25 https://youtu.be/PboNpugAP2s. en lo que se refiere al abordaje de la problemática de las personas sin hogar. Desarrollado inicialmente en Estados Unidos a finales de la década de 1990, y estrechamente vinculado a los enfoques de atención centrada en la persona y desinstitucionalización explicados en el epígrafe anterior, este modelo de intervención en el ámbito del sinhogarismo ha ido extendiéndose a lo largo de los últimos años a muy diversos países y forma ya parte de las estrategias oficiales de prevención y tratamiento de la exclusión residencial en diversos países de Europa.

En nuestro entorno más cercano, el modelo Housing First está siendo desarrollado en el Estado español a través del programa Hábitat de Hogar Sí (antes, Fundación RAIS) ${ }^{26}$. La propia Estrategia Nacional Integral para Personas Sin Hogar aprobada en 2015 por el Gobierno central aboga por el impulso de este tipo de actuaciones, que forman parte también de las estrategias nacionales de abordaje de la exclusión residencial de diversos países. En la Comunidad Autónoma del País Vasco se han puesto ya en marcha iniciativas específicas en Bizkaia y Gipuzkoa (Cadena Ser, 2016), impulsadas por las diputaciones forales de esos territorios y por los ayuntamientos de Bilbo y Donostia.

¿En qué consiste este modelo? Housing First se caracteriza principalmente por los siguientes elementos:

- Entender el alojamiento como un derecho humano fundamental al que deben tener acceso todas las personas.

- Partir del principio de que las personas toman todas las decisiones que les afectan; por lo tanto, los equipos de profesionales están para apoyar en ese proceso y para ayudar a que las personas puedan llevar a la práctica sus decisiones. Cualquier apoyo que se preste pone a la persona y sus necesidades en el centro.

- Tender a la normalización, huyendo de guetos de vivienda o de formas de alojamiento en las que se concentren personas que partían de una situación de exclusión social.

- Concebir la vivienda como el lugar de residencia, de intimidad y de seguridad de cada persona; si es necesario algún tipo de tratamiento, este se realizará desde los recursos y servicios a los que accede el resto de la ciudadanía.

- Entender la comunidad (el bloque en el que las personas viven, el barrio) como un espacio de oportunidades para recuperar la relación con el entorno y construir una red social de apoyo.

De acuerdo con Llobet y Aguilar Hendricksón (2016: 6), “el mandato del modelo Housing First es conseguir la estabilización de la persona en la vivienda, su mejora y recuperación, y su incorporación social y comunitaria. Este mandato

\footnotetext{
${ }^{26}$ https://hogarsi.org/habitat/.
} 
está conectado con una lógica de acción centrada en la persona y en el reconocimiento de derechos, que reclama explorar una práctica fundamentalmente relacional. Reconocer el derecho (no condicionado al tratamiento) a la vivienda supone renunciar al uso de un poderoso motivo externo a la persona para incentivar su participación en el tratamiento y el cambio de sus comportamientos. Esto supone que la intervención debe recurrir fundamentalmente a las motivaciones intrínsecas de la persona, que están conectadas con sus necesidades, intereses y deseos. Esta es una de las diferencias importantes respecto al modelo de Escala de atención, que se centra más en las motivaciones extrínsecas, que vienen acompañadas de contrapartidas y/o condiciones".

A partir de estos criterios, se puede decir que las bases conceptuales del modelo son tres:

- Por una parte, la disociación entre la provisión de una vivienda y la provisión de los apoyos socioeducativos y psicosociales necesarios para la inclusión social. El modelo Housing First forma así parte de una orientación más amplia, aplicada en numerosos países en el ámbito de la exclusión residencial, que podría definirse como enfoque basado en la vivienda (housing led policies). De acuerdo con la Conferencia de Consenso sobre el Sinhogarismo de 2010 (Vandenbroucke et al., 2010), las políticas centradas en la vivienda son todas aquellas que identifican la provisión o mantenimiento de una vivienda estable como el paso inicial para prevenir o resolver las situaciones de sinhogarismo. Estos enfoques consideran la vivienda como un derecho fundamental y un prerrequisito para la resolución de otros problemas sociales, laborales o de salud. Desde esta perspectiva, el factor que subyace a la exclusión residencial es la carencia de una vivienda y no necesariamente la pobreza o la exclusión social, por lo que proveer de una vivienda a esas personas se considera la base para cualquier otro tipo de intervención. Complementariamente, este enfoque implica que son los servicios de vivienda, y no los servicios sociales, los que deben asumir el protagonismo en relación con la prevención y el abordaje de la exclusión residencial extrema.

- La segunda idea básica que subyace a este modelo es la crítica al modelo condicional o en escalera en el que se basan buena parte de los actuales recursos de atención a las personas sin hogar. En efecto, los enfoques centrados en la vivienda suponen una ruptura con los modelos de intervención escalonada o lineal, en virtud de los cuales los itinerarios de inclusión solo pueden iniciarse en el momento en que la persona usuaria está preparada para un proceso de cambio y en el que las personas sin hogar van superando escalones a través de diversos servicios residenciales, vinculados a la resolución de cuestiones sociales y de salud antes de convertirse en lo que llaman housing-ready (personas preparadas para acceder a una vivienda).
Este modelo lineal implica un continuo de atención, o itinerario de inclusión, a través del cual la persona en situación de exclusión progresa o avanza de forma paulatina: en el caso de las personas sin hogar, el itinerario partiría de los centros de baja exigencia o bajo umbral, pasaría a los recursos residenciales convencionales de corta estancia y, de ahí, a los modelos de vivienda tutelada o con apoyo, con niveles de autonomía más elevados y menor intensidad de apoyo. Se trata de un modelo escalonado y la ubicación de las personas en alojamientos autónomos o independientes se produce únicamente al final de esos procesos, una vez recorrido el itinerario completo. La superación de una serie de conductas o actitudes -entre ellas, los consumos de drogas- y la aceptación de una serie de normas, como la abstinencia, se plantean en este tipo de modelos como prerrequisito para el avance en ese continuo y el acceso a modelos residenciales autónomos (Johnsen y Teixeira, 2010).

- Junto con ese cuestionamiento de la intervención lineal o en escalera, el modelo Housing First se basa también en los conceptos de reducción de daños y de baja exigencia, en un marco de intervención caracterizado por la incondicionalidad. En efecto, el concepto de reducción de daños es un componente esencial del modelo Housing First en la medida en que plantea un modelo de atención a las dependencias "a demanda”, en el que no se fuerza a las personas usuarias a participar en determinados tratamientos y en el que el acceso a la vivienda no se condiciona a la participación en tales programas. Este enfoque implica la posibilidad de que las personas que participan en estos programas puedan mantener sus consumos - siempre que no molesten a otras personas-, la necesidad de que la oferta de vivienda se complemente con la existencia de recursos sociosanitarios para la reducción de daños (como salas de consumo supervisado o programas de reparto de jeringuillas), y la adopción de cambios organizativos que permitan combinar los servicios de apoyo en la vivienda y de reducción de daños (Pauly et al., 2013).

En realidad, lo que este modelo hace es trasladar al ámbito de la atención a las personas sin hogar algunos conceptos y principios que -teóricamente al menos- han sido ampliamente asumidos en otros ámbitos de los servicios sociales, como la atención a las personas mayores o a las personas con discapacidad: la individualización de la atención, la centralidad del concepto de calidad de vida, la apuesta por la utilización de viviendas o equipamientos residenciales de pequeño tamaño y bien integradas en la comunidad, el énfasis en el control y la autodeterminación por parte de las personas usuarias, y el protagonismo de los conceptos de reducción de daños y baja exigencia.

De acuerdo con lo apuntado por Pleace y Bretherton (2013), existe suficiente evidencia para afirmar que 
el enfoque basado en la vivienda es muy efectivo para reducir el sinhogarismo entre los colectivos con mayores necesidades de apoyo. Este enfoque enfatiza la necesidad de tratar a las personas sin hogar con necesidades intensas de apoyo con respeto, ofrecerles opciones de elección y control sobre sus vidas, y apoyarles para su reintegración en la sociedad mediante la provisión inmediata de una vivienda.

¿Funciona este enfoque? El modelo Housing First es, probablemente, una de las intervenciones que ha sido sometida a más análisis y evaluaciones en el ámbito de la intervención social. En efecto, son muchísimos los ensayos, pilotos y evaluaciones realizados a lo largo de los últimos años, con resultados en general positivos. Entre otros, se han llevado a cabo evaluaciones rigurosas en países como Canadá (Aubry et al., 2015), Bélgica (Housing First Belgium, 2014), Inglaterra (Bretherton y Pleace, 2015) o Escocia (Johnsen, 2013), donde este enfoque forma parte de la estrategia nacional de atención a las personas sin hogar.

El estudio europeo más conocido es en cualquier caso el realizado con apoyo de la Comisión Europea en diez ciudades de otros tantos países por Volker Busch-Geertsema (2013). De acuerdo con esa evaluación, el programa obtiene altas tasas de retención y la calidad de vida de las personas que acceden a él aumenta de forma ostensible, con mejoras en lo que se refiere a los problemas de salud mental y de consumo de drogas, si bien los resultados no resultan tan alentadores desde el punto de vista del acceso al empleo, la gestión de los recursos económicos, la integración social o las relaciones personales y con el vecindario. Por otra parte, en la mayor parte de los casos analizados el programa requiere menos recursos económicos que las intervenciones tradicionales, si bien es necesario avanzar en la realización de estudios de costeefectividad más concluyentes.

Los proyectos de Housing First españoles también empiezan a arrojar resultados. Son particularmente interesantes los recogidos en la ciudad de Barcelona (Fortea y Herruz, 2017; Matuliĉ, Cabré y García, 2016). Del mismo modo, las evaluaciones realizadas por Hogar Sí - entidad pionera en España en el desarrollo de estos servicios- ponen de manifiesto resultados muy positivos (Bernad, Yuncal y Cenjor, 2016). A partir de un diseño experimental en el que participan cien personas sin hogar (divididas en dos grupos: el grupo participante en el programa Hábitat y otro que recibe la intervención tradicional), el programa ha demostrado ser más eficaz que las alternativas tradicionales de intervención con un coste económico similar. En efecto, las personas participantes en Hábitat reducen el uso de recursos sociales de emergencia y necesidades básicas (equipos de calle o centros de día) y aumentan el uso de recursos de rehabilitación y reinserción (talleres formativos, atención psicológica o psiquiátrica, rehabilitación). De la evaluación de eficiencia económica se deriva por tanto, de acuerdo con sus promotores, que el coste de Hábitat es similar o menor que el de otro tipo de recursos de la red de personas sin hogar, pero con una intervención de mayor intensidad y más efectiva.

De los resultados destaca extraordinariamente la estabilidad en el alojamiento. El perfil de personas participantes tiene enormes dificultades para acceder o mantener las plazas en los recursos de alojamiento tradicionales para personas sin hogar, por lo que acaban durmiendo de manera continuada en las calles. El $100 \%$ de las personas participantes en Hábitat han pasado de vivir establemente en la calle a permanecer, un año después de su entrada, en la vivienda que les facilita el programa.

De acuerdo con la información publicada por la propia fundación, estos son otros resultados destacados de la intervención:

- La calidad de vida (índice QoLI) de las personas participantes ha mejorado notablemente en poco tiempo.

- Las personas en las viviendas sufren menos agresiones, insultos y vejaciones y su sensación de seguridad ha aumentado notablemente.

- Muchas de estas personas han recuperado las relaciones familiares y ha disminuido su sensación de soledad.

- En cuanto a la salud, destacan las mejoras con respecto a síntomas frecuentes en las personas sin hogar como la ansiedad y el insomnio.

Parecen obvios por tanto los beneficios que frente a las alternativas tradicionales suponen los programas de Housing First. Es en cualquier caso necesario reflexionar también sobre sus límites. La literatura consultada permite hacer referencia a las siguientes limitaciones:

- Se han puesto de manifiesto los insuficientes resultados de estos programas desde el punto de vista de la integración social o relacional de estas personas, que no por residir en una vivienda abandonan -en ocasiones ocurre al contrario- la situación de soledad o aislamiento en la que viven. En ese sentido, las revisiones (Pleace y Quilgars, 2013; Quilgars y Pleace, 2016) realizadas en relación con esos programas indican que la idea de housing first no equivale a housing only y que la mera provisión de una vivienda no es suficiente para permitir que estas personas avancen hacia mayores cotas de inclusión.

- Otra de las limitaciones se refiere al riesgo de considerar que con la aplicación de este tipo de enfoques se da solución al conjunto de las personas sin hogar. Al contrario, los promotores de este tipo de orientaciones defienden que están dirigidas a un subgrupo específico de las personas sin hogar -las que tienen un problema de salud mental, discapacidad o adicciones-, 
por lo que será necesario seguir ofreciendo otro tipo de intervenciones a las personas que no se corresponden con ese perfil.

- Finalmente, también cabe hacer referencia al riesgo de que se conviertan en una intervención puntual, exclusivamente desarrollada desde el ámbito de los servicios sociales, y que su aplicación no se traduzca en un cambio más generalizado de paradigma, es decir, en una asunción más sistemática por parte del sistema de vivienda de su responsabilidad en el ámbito de la exclusión residencial y en un mayor énfasis en la prevención de las situaciones de sinhogarismo.

\section{Hacer que el trabajo compense ('making work pay')}

En el complejo debate sobre cómo hacer frente al problema de garantizar una renta en las sociedades contemporáneas, una de las propuestas que más eco ha tenido en algunos países es la de aumentar la renta de los hogares a través de algún tipo de complemento de los salarios. Instrumentados de distintas formas, estos complementos tratan de hacer frente a distintas necesidades, siendo las dos más subrayadas en su justificación la mejora de la renta disponible de los hogares y los incentivos al empleo. Se señala en su defensa que este tipo de subsidios laborales son más eficientes que las prestaciones asistenciales, al impedir, en lugar de favorecer, la posible generación de cadenas de dependencia, aumentando la participación laboral de los trabajadores menos cualificados. Se argumenta en su contra, sin embargo, que podrían dar lugar a reducciones salariales por parte de los empleadores, haciendo descansar en la iniciativa pública la financiación de la caída de los ingresos (Ayala y Paniagua, 2019).

Ampliamente desarrolladas a lo largo de las dos últimas décadas, las medidas de "rentabilización del empleo" o making work pay pretenden combinar de manera más ágil la percepción de prestaciones de garantía de ingresos y el desempeño de un puesto de trabajo de baja remuneración, con dos objetivos básicos: por una parte, evitar el desincentivo a la inclusión laboral que -debido al principio diferencial en el que se basan las prestaciones de garantía de ingresos- supone la escasa, o nula, diferencia entre los ingresos derivados de una prestación y los que se obtienen del acceso a un puesto de trabajo con un salario bajo, garantizando unos ingresos más elevados a las personas que acceden a un empleo; por otra, reducir las tasas de pobreza de los trabajadores y trabajadoras de bajos salarios. Este enfoque ha venido siendo crecientemente adoptado en el diseño de las prestaciones de garantía de ingresos para dar respuesta a la mutación del empleo al que normalmente acceden las personas perceptoras, que se caracteriza tanto por salarios bajos como por su carácter discontinuo e intermitente.
Para dar respuesta a estas problemáticas - la trampa de la inactividad, la insuficiente remuneración de un número creciente de empleos y su discontinuidadse han desarrollado en diversos países una serie de políticas que, englobadas en el marco genérico de la activación, se adscriben a la filosofía del making work pay. Difícil de expresar en castellano a través de una expresión tan gráfica como la original, la expresión inglesa making work pay podría traducirse como "hacer que el trabajo compense" o "rentabilización del empleo". Las medidas que se incluyen en este grupo basculan en general entre dos grandes objetivos: por una parte, la incitación al empleo, en la línea del paradigma de la activación, a partir de la idea de que es necesario incentivar o estimular el acceso al empleo de las personas inactivas o perceptoras de prestaciones económicas para evitar la trampa de la pobreza. Al mismo tiempo, estas medidas también tienen en general un marcado carácter redistributivo y aspiran a reducir las tasas de pobreza entre la población asalariada.

El principal objetivo de las políticas de making work pay es hacer más sencilla la compatibilización de un salario de baja cuantía con la percepción, puntual o indefinida, de una prestación asistencial de garantía de ingresos. Desde ese punto de vista, este tipo de prestaciones buscan suavizar el principio diferencial en el que se basan las políticas tradicionales de garantía de ingresos - la prestación se calcula restando de una cuantía prestacional máxima el $100 \%$ de los ingresos laborales, lo que implica que se establece una imposición del $100 \%$ sobre esos ingresos- y que genera la señalada trampa de la pobreza o la inactividad. En el caso de las prestaciones englobadas bajo el paraguas del making work pay, la lógica es la contraria: lo que se garantiza es una prestación máxima, que actúa como ingreso mínimo garantizado. Las personas que carecen de ingresos propios acceden por tanto a esa prestación máxima, con la cual se les garantiza un ingreso mínimo determinado. Cuando existen ingresos propios, la prestación abonada se reduce progresivamente, pero no a una tasa del 100\% (la prestación no se reduce en un euro por cada euro ganado), sino a tasas menores, de forma que, por ejemplo, por cada euro de remuneración salarial la prestación se reduce en 40 céntimos, hasta que llega un nivel salarial en el que la ayuda desparece. De esa forma, el desempeño de una actividad laboral resulta siempre, en teoría, más rentable que la percepción del ingreso garantizado, los ingresos totales crecen a medida que crece el salario y se protege al mismo tiempo a los trabajadores con menores ingresos, así como a quienes carecen de ingresos.

Los países que han desarrollado este tipo de medidas lo han hecho mediante dos mecanismos diferentes:

- Una parte importante de las políticas de making work pay se han desarrollado mediante el sistema fiscal, preferentemente a través de la figura de las deducciones fiscales reembolsables, que se 
abordan en el punto siguiente. Los dispositivos que han conocido un mayor grado de desarrollo en ese sentido son el británico Working Family Tax Credit (WFTC) y el norteamericano Earned Income Tax Credit (EITC), que representa una de las principales herramientas contra la pobreza muy por delante de las prestaciones económicas asistenciales- de aquel país. También se han desarrollado herramientas de este tipo en Francia, Bélgica, Finlandia, Dinamarca y los Países Bajos, así como en Canadá, Nueva Zelanda y en el territorio español de régimen común, mediante el impuesto negativo reconocido primero a las madres ocupadas con hijos o hijas menores de tres años y, después, a familias numerosas y personas con discapacidad.

- Otros sistemas (Francia - que en cualquier caso combinó durante años las dos aproximaciones-, Alemania, el País Vasco o, desde hace poco, el Reino Unido ${ }^{27}$ ) han optado por el contrario por incluir este tipo de sistemas dentro del propio diseño de la prestación de garantía de ingresos. Si bien las fórmulas utilizadas para ello son diversas, la idea fundamental radica en la suavización del principio diferencial asociado a la prestación, de forma que los ingresos laborales no se tienen íntegramente en cuenta a la hora de calcular los ingresos propios y, por tanto, la prestación asistencial correspondiente.

La Comunidad Autónoma del País Vasco (CAPV) ha sido pionera en la aplicación de este tipo de enfoques, mediante el sistema de estímulos al empleo, que ahora se extienden a otras comunidades, como Navarra. Aunque no puede hablarse de resultados concluyentes, una buena parte de las evaluaciones que se han realizado en relación con estos sistemas han arrojado resultados positivos.

En el caso de la CAPV, aun con las limitaciones introducidas en los últimos años, las escasas evaluaciones realizadas prueban que el sistema de estímulos al empleo vinculado a la Renta de Garantía de Ingresos (RGI) ha sido capaz de reducir de forma significativa el fenómeno de la pobreza laboral entre la población vinculada al mercado de trabajo en Euskadi. Lo ha hecho además sin arrastrar a la baja los salarios y consiguiendo una tasa de acceso a la prestación superior a la que se registra en países que han dedicado mayores recursos a estas prestaciones (Zalakain, 2014). En el caso de Navarra, un reciente estudio del Observatorio de la Realidad Social del Gobierno de Navarra (Observatorio de la Realidad Social, 2018), pone de manifiesto que durante el periodo analizado (de noviembre de 2016 a noviembre de 2017) hubo 22.954 personas de entre 16 y 64 años que percibieron la renta garantizada. De ellas, 6.225 (el $27,1 \%$ ) la compatibilizaron con

${ }_{27}$ El Reino Unido, que durante años desarrolló mediante el Working Tax Credit este sistema de deducciones fiscales reembolsables, está sustituyendo esa aproximación, de forma progresiva, por una prestación (Universal Credit) basada en el mismo principio. un empleo, siendo así beneficiarias de estímulos al empleo. Según la evaluación realizada, la normativa relativa a la Renta Garantizada (RG) y los estímulos al empleo ha posibilitado un ligero aumento en cifras absolutas de las personas que han podido compatibilizar esos empleos con la propia RG, mejorando de esta forma su situación económica. Pese a que no parece apreciarse que esta normativa haya supuesto un incremento significativo de las personas beneficiarias de RG con contratos, lo que ha variado es que sigan siendo beneficiarias a través de los complementos de ingresos y que esa conjunción resulte más estable, es decir, con menos interrupciones o intermitencias.

También resulta de interés la experiencia francesa. En 2009, el sistema de prestaciones de garantía de ingresos de aquel país se reformó radicalmente al objeto de permitir una mayor compatibilidad de los ingresos salariales bajos y las prestaciones asistenciales. En 2016, se optó por diferenciar el complemento salarial de la renta garantizada, creándose la prima de actividad (Prime d'activité) ${ }^{28}$, que hoy perciben más de cuatro millones de personas. La cuantía media de la prestación es de 186 euros mensuales, con un gasto público total de unos 8.000 millones de euros.

En términos más generales - si bien es cierto que, dada la diversidad de objetivos y de potenciales beneficiarios, no es siempre fácil identificar o aislar adecuadamente el efecto de estas prestaciones ${ }^{29}-$, sí cabe pensar que algunos de los modelos desarrollados en nuestro entorno han tenido resultados razonablemente buenos En todo caso, junto con los resultados en general positivos que se atribuyen a estos programas, también es necesario hacer hincapié en sus riesgos. En ese sentido se ha puesto de manifiesto que "pueden interpretarse como una subvención al capital que, ante la existencia

\footnotetext{
${ }^{28}$ https://youtu.be/jAHnzVhvjZs.
}

29 De acuerdo con Ayala y Paniagua (2019: 137), “para un mejor funcionamiento de esta figura, parece necesario combinarla con otro tipo de recursos dentro del sistema de prestaciones e impuestos. Hacer descansar el grueso de la protección social en los complementos salariales o desarrollarlos sin conexión con otras prestaciones puede reducir la capacidad redistributiva del sistema. Especialmente importante es la complementariedad con las prestaciones familiares cuando los ingresos del conjunto del hogar intervienen en el cálculo de la prestación. Los estudios para varios países muestran que la sensibilidad a las horas trabajadas en las familias con hijos pequeños es mayor que en el caso de otros colectivos. La existencia de costes fijos importantes en la transición al empleo requiere que, para que aumente la participación laboral, no haya una brecha importante entre el salario bruto y el neto. En general, los trabajos que han estudiado los cambios de la oferta de trabajo ante modificaciones de los tipos marginales de las rentas ganadas por trabajar un mayor número de horas muestran que su reducción puede afectar positivamente a la participación laboral de las mujeres que habitualmente cobran salarios bajos. Ese efecto es mayor si existe otro perceptor de rentas en el hogar. Para que los complementos salariales tengan un mayor impacto social también es importante el modo en que se combinan con avances en otras políticas relacionadas con el mercado de trabajo, como las prestaciones de desempleo, las políticas de activación o la propia regulación del salario mínimo. Considerarlos de manera aislada, como se acaba de señalar, reduce considerablemente sus posibilidades, tanto de convertirse en un instrumento redistributivo suficientemente sólido como de impulsar las transiciones desde la inactividad al empleo". 
de los mismos, queda dispensado de remunerar adecuadamente a la mano de obra, transfiriéndose a la colectividad una parte de la responsabilidad de las empresas" (De la Cal, 2015: 9)30.

El resultado de las evaluaciones realizadas es por tanto ambivalente. Para Ayala y Paniagua (2019: 148), "las experiencias de distintos países, sobre todo los anglosajones, parecen indicar que en determinadas condiciones estos complementos pueden producir efectos netos positivos sobre la participación laboral y una reducción de la incidencia de la pobreza. No obstante, de la evidencia disponible hasta el momento se desprende también que hay determinadas características de estos programas que pueden dar lugar a efectos contradictorios".

En relación con el caso español, añaden estos autores, "las evaluaciones de algunos de los componentes del sistema actual de impuestos y prestaciones permiten anticipar un posible efecto positivo en la incorporación al mercado laboral de un número no desdeñable de mujeres. Pero los efectos globales de un complemento salarial no son evidentes. Para que las posibles ganancias de eficiencia y equidad derivadas de un complemento salarial fueran posibles, tendría que darse un aumento muy importante de la contratación por parte de los empleadores. Sin cambios desde el lado de la demanda, esos efectos redistributivos apenas se notarían. Podría producirse, además, un aprovechamiento de este tipo de instrumentos para reducir los costes salariales e imponer al sector público la financiación de esa brecha a través de estos complementos” (Ayala y Paniagua, 2019: 149).

\section{Integración de las políticas sociales y fiscales}

Si bien en nuestro entorno se tiende en general a analizar de forma separada el sistema fiscal y el de protección social (atribuyendo al primero una función recaudatoria y al segundo una función redistributiva y asistencial), lo cierto es que en gran parte de los países de nuestro entorno se está produciendo una mayor integración de ambas esferas, y que tanto los análisis como las reformas de las políticas tienden crecientemente a referirse conjunto del sistema sociofiscal (tax benefits system). De acuerdo con una reciente revisión de este tipo de herramientas (Zalakain, 2019), el recurso al sistema fiscal para dar respuesta a determinadas necesidades sociales e incluso para canalizar ciertas prestaciones económicas resulta cada vez más frecuente y generalizado, especialmente en el ámbito de las políticas de apoyo a las familias y de garantía de ingresos. En efecto, como explican Ferrarini, Nelson y Höög (2012), las políticas sociales de buena parte

\footnotetext{
${ }^{30}$ Algunos autores han señalado en ese sentido que ese tipo de prestaciones están haciendo que las políticas públicas de empleo pasen de la creación directa de empleo a la financiación parcial del empleo privado de menor cualificación (Kenworthy, 2015).
}

de los países occidentales asisten en los últimos años a un proceso de fiscalización, de tal forma que una parte de las prestaciones económicas que anteriormente gestionaban la Seguridad Social o los sistemas de asistencia social en forma de prestación directa se canalizan ahora mediante deducciones o desgravaciones fiscales.

Dentro de este proceso de fiscalización coexisten dos tipos de enfoques diferentes que parten de lógicas contrapuestas. Las deducciones tradicionales se limitan a reducir la deuda tributaria de los contribuyentes y se basan por tanto en una lógica de reducción de la presión fiscal para los contribuyentes de ingresos medios o bajos. Por definición, no benefician -o lo hacen en muy escasa medida- a los contribuyentes de muy bajos ingresos, con responsabilidades tributarias demasiado pequeñas para beneficiarse de una rebaja de impuestos, o a quienes carecen de ingresos. Por el contrario, las deducciones reembolsables (más conocidos en la literatura anglosajona como refundable tax credits) benefician a todas las personas potencialmente beneficiarias, ya que si el montante de la deducción es superior a la deuda tributaria, la diferencia se abona a las personas contribuyentes como una prestación neta. Estas herramientas plantean algunas ventajas - normalización, simplificación, menor estigmatización, etc.- pero también algunas desventajas que es necesario subrayar.

En líneas generales, estas deducciones se diferencian del resto de las deducciones fiscales en el hecho de que no están limitadas a la deuda tributaria del contribuyente: la deducción reembolsable reduce la deuda con Hacienda hasta cero -como ocurre con el resto de las deducciones-, pero si la deducción es superior a la cuota, la diferencia se convierte en una transferencia neta que se abona al contribuyente. El carácter reembolsable de estas deducciones resulta desde ese punto de vista un elemento esencial, ya que, como explican McCabe y Popp (2016), traslada el énfasis político de la lógica de la reducción de impuestos a la lógica de la redistribución.

En ese marco general, los créditos fiscales reembolsables se han utilizado básicamente con tres finalidades, a menudo interrelacionadas:

- Desarrollar las políticas de apoyo a las familias con hijos e hijas, complementando otras prestaciones económicas que puedan existir, y reducir la incidencia de la pobreza infantil.

- En la óptica de la activación, reducir los desincentivos al empleo que pueden tener aparejados los sistemas ordinarios de rentas mínimas y estimular el acceso al empleo de los perceptores de rentas mínimas.

- Desde esa misma óptica, proteger a los trabajadores de bajos salarios y mejorar las políticas redistributivas dirigidas a ese colectivo, haciendo frente de esa forma a la erosión de la capacidad inclusiva del empleo que supone el 
fenómeno de los trabajadores pobres o working poors.

A estos tres objetivos básicos pueden añadir dos finalidades complementarias:

- Por un lado, contribuir a la simplificación, normalización y “legilibilidad” del sistema fiscal y prestacional, evitando los elevados niveles de non take up o no recurso a las prestaciones económicas que se registran, los errores y cobros indebidos, o el exceso de gasto en gestión y administración. En lo que se refiere a la normalización del sistema, estos modelos se alejan de los principios de condicionalidad que habitualmente se asocian a las rentas mínimas de inserción y -sin abandonar, lógicamente, su carácter selectivo y condicionado- apuestan por un modelo de garantía de rentas más automático, sencillo y normalizado, en la medida en que se integran en un dispositivo -el fiscal-dirigido al conjunto de la población y se limitan a complementar unos ingresos laborales considerados insuficientes.

- Por otro lado, contribuir a dotar al sistema fiscal de una mayor progresividad, extendiendo a las rentas más bajas los beneficios que los grupos con rentas más altas han venido obteniendo de las rebajas impositivas y facilitando un tratamiento fiscal más beneficioso a las familias con hijos o a los trabajadores con bajos salarios.

Junto con estos elementos, es necesario señalar otras características básicas de este tipo de herramientas:

- Se trata de herramientas fiscales especialmente desarrolladas en los países anglosajones - se han definido como un pilar básico de un emergente modelo "anglosocial” de carácter transoceánicoy están muy vinculadas a la "tercera vía" socialdemócrata. No debe olvidarse que fueron especialmente impulsadas por políticos como Bill Clinton, Tony Blair o Gordon Brown.

- No se trata de prestaciones universales ni incondicionales: a menudo se orientan únicamente a quienes tienen ingresos laborales y en general se reducen a medida que crecen los ingresos, hasta desaparecer a partir de unos ingresos determinados. Buscan, desde ese punto de vista, incentivar el acceso al empleo de bajos salarios y en pocos casos se orientan a personas inactivas.

- En general, son sistemas complementarios a las prestaciones económicas convencionales, si bien en algunos casos las personas potencialmente beneficiarias han de optar entre un sistema $u$ otro.

- Se aplican en general como deducciones en la cuota y coexisten con otros beneficios fiscales (mínimos vitales, bonificaciones por trabajo, reducciones por tributación conjunta, exención de determinados ingresos $u$ otras deducciones), así como con el resto de las características que definen un sistema fiscal determinado (tipos, tramos o mínimos exentos).

En la revisión realizada por el SIIS se describe el funcionamiento de una treintena de deducciones fiscales desarrolladas en una docena de países de Europa, América y Oceanía. Sin duda, los más destacados, y los que han sido evaluados y analizados con mayor rigor, son el Earned Income Tax Credit (EITC) ${ }^{31}$ estadounidense y el sistema de tax credits británico (formado por el Working Tax Credit y el Children Tax Credit), actualmente en fase de desmantelamiento.

El EITC estadounidense es, sin duda alguna, el principal referente internacional en lo que a los créditos fiscales reembolsables se refiere, tanto desde el punto de vista de su cobertura y del gasto realizado como de su papel en el sistema de protección social norteamericano. En 2017, el Gobierno estadounidense destinó 68.000 millones de dólares (lo que supone un 0,32\% del PIB) al EITC, que es sin duda el principal programa de lucha contra la pobreza en Estados Unidos. Para el año 2016, se calcula que se beneficiaron de esta ayuda en torno a 28 millones de contribuyentes, con una deducción media de 2.440 dólares.

En Europa, aunque está llamado a desaparecer en breve, se mantiene parcialmente vigente el sistema de créditos fiscales del Reino Unido, uno de los principales exponentes en el continente europeo de este tipo de enfoques. También en el Estado español están teniendo estas herramientas un cierto desarrollo. El territorio de régimen común cuenta por ejemplo con una serie de deducciones fiscales reembolsables a las que pueden acceder, por una parte, las mujeres ocupadas con hijos o hijas menores de tres años y, por otra, las familias numerosas y las que tienen ascendientes o descendientes con discapacidad. En ambos casos se trata de una deducción parcialmente reembolsable que puede ser percibida de forma anticipada y en pagos mensuales.

La Comunidad Foral de Navarra también ha avanzado por esta línea mediante las deducciones fiscales anticipadas a las que acceden las personas que perciben pensiones de viudedad con derecho a complementos por mínimos o pensiones de viudedad del antiguo seguro obligatorio de vejez e invalidez (SOVI) y pensiones no contributivas de jubilación que reúnen los requisitos para tener derecho a la renta garantizada. El anticipo se solicita en los servicios sociales de base o en el propio Departamento de Derechos Sociales, se abona por parte del Departamento de Hacienda y se computa como gasto fiscal. El cobro anticipado implica la no realización de la deducción en caso de realizarse declaración de IRPF. En 2017 se beneficiaron de esta deducción cerca de 15.000 personas, con un gasto de 12,9 millones de euros, frente a los 2,5 de 2015.

\footnotetext{
${ }^{31}$ https://youtu.be/TXsdp6SDKcY.
} 


\section{Modelos de ventanilla única e integración de servicios (ERSISI)}

Los modelos de ventanilla única (one stop shops) son definidos en el ámbito de las políticas activas de empleo como soluciones administrativas dirigidas a unificar o combinar la prestación de servicios de empleo, la gestión y provisión de prestaciones económicas - contributivas y no contributivas-y los servicios sociales a las personas desempleadas en un único punto de atención y de forma coordinada o integrada, con el objetivo de maximizar la mejora de la empleabilidad y las posibilidades de incorporarse al mercado de trabajo de las personas desempleadas. Las dificultades sociales que presentan muchas de las personas desempleadas de larga duración hacen que estas sean usuarias de varios servicios públicos de forma simultánea (Bouget et al., 2015).

De hecho, la atención a este grupo de población suele implicar, al menos, a los servicios públicos de empleo, a los servicios del sistema de garantía de ingresos y, en algunos casos, también a los servicios sociales. Por otro lado, la mayor presencia de personas con importantes barreras de acceso al empleo entre este grupo de población hace que muchas veces sea necesario complementar las medidas de activación con la provisión de servicios sociales y otros servicios complementarios que aumenten la empleabilidad de las personas e incrementen la sostenibilidad de sus procesos de inserción sociolaboral (Minas, 2009). Por eso la búsqueda de una adecuada coordinación entre los principales servicios que atienden a esta población constituye un eje estratégico para mejorar la calidad de la atención prestada e incrementar la eficacia de las políticas públicas dirigidas a este grupo de población ${ }^{32}$.

En la última década, la mayoría de los países europeos han llevado a cabo reformas dirigidas a integrar los servicios que atienden a los grupos de población con necesidades más complejas, precisamente, para aumentar la eficiencia en el uso de los recursos y mejorar la calidad de los servicios prestados (Van Berkel y Borghi, 2008). La forma que esta idea ha tomado en la práctica varía entre los distintos países europeos, lo que hace difícil definir de forma detallada el concepto de ventanilla única a partir del contenido y la estructura de los servicios existentes en el contexto europeo. Minas

${ }^{32}$ En la actualidad, los problemas de coordinación entre los servicios sociales y los de empleo plantean problemas importantes para el adecuado funcionamiento de los programas de incorporación laboral. De acuerdo con Fernández (2015: 62), "si bien es cierto que la efectividad de la coordinación entre los niveles centrales y regionales del Servicio Público de Empleo ha mejorado (en parte, porque comparten espacios físicos y desarrollan un sistema de información común), la coordinación entre los servicios sociales y de empleo es débil debido a su dispersión entre distintos departamentos, las lógicas profesionales distintas, limitada interconexión y escaso intercambio de información. Esta distancia se alimenta además de las distintas lógicas institucionales de un servicio de empleo orientado al desempleo y unos servicios sociales orientados a la exclusión".
(2014) propone una clasificación que establece dos grandes modelos de ventanilla única en el marco de las políticas de empleo en Europa: los países donde los servicios integrados solo abarcan a los servicios de empleo y los sistemas de protección económica o garantía de ingresos, por una parte, y los países donde los servicios integrados incluyen a los servicios de empleo, los sistemas de garantía de ingresos y los servicios sociales para personas desempleadas, por otra. Pese a que hay numerosos documentos que analizan de forma descriptiva la creación de servicios integrados en el contexto europeo, existen pocas evaluaciones integrales de las reformas implementadas y, sobre todo, hay pocos datos de carácter cuantitativo que permitan medir el efecto de estas reformas sobre las oportunidades de empleo de las personas desempleadas (McQuaid, 2007). Si bien en los casos en que existen datos los estudios muestran que el establecimiento de los servicios integrados ha mejorado el acceso de las personas desempleadas de larga duración a los servicios y programas de activación, así como a los sistemas de protección económica, esta mejora en el acceso a los sistemas no siempre acaba traduciéndose en una mejora de las oportunidades de empleo en el mercado de trabajo ordinario.

En nuestro entorno, uno de los programas experimentales de integración de servicios sociales y de empleo más sólido -si bien de carácter experimental- es el proyecto ERSISI ${ }^{33}$, impulsado por el Gobierno de Navarra y desarrollado en las comarcas de Sakana y Tudela. En las localidades de Tudela, Alsasua, Olazagutía y Ziordia, este proyecto europeo ha promovido un modelo de atención de las personas vulnerables desempleadas (especialmente perceptoras de renta garantizada) basado en el trabajo conjunto de los servicios sociales y las agencias de empleo para apoyar el ejercicio del derecho a la inclusión social y la incorporación sociolaboral. Para ello ha desarrollado herramientas diagnósticas que permiten segmentar a las personas beneficiarias en función de sus necesidades prioritarias, así como planificar respuestas coordinadas e integradas entre los dos servicios.

El proyecto ERISISI partió de la hipótesis de que la protección económica que representa el derecho a una renta garantizada (Ley Foral 15/2016) no tenía por qué desincentivar que las personas perceptoras desempleadas buscaran reinsertarse en el mercado laboral si, junto con dicha protección, se les proporcionaba un apoyo personalizado, integral e intenso para guiarlas hacia la activación. Esta hipótesis se ha visto validada, según ha afirmado el equipo evaluador del proyecto (del Departamento de Sociología y Trabajo Social de la Universidad Pública de Navarra) que ha comparado datos de las 502 personas beneficiarias con un grupo de control de idéntico tamaño y similares características utilizando una metodología de evaluación contrafactual.

${ }^{33} \mathrm{https} / /$ youtu.be/WGQU_20NVaM. 
Según sus evaluadores, el proyecto ha tenido en primer lugar consecuencias en la utilización de recursos para la activación (orientación y formación). Antes de su llegada al proyecto ERSISI, en torno a un $70 \%$ de sus 502 personas beneficiarias no habían realizado actividades en los doce meses anteriores. En cambio, durante su participación en el proyecto realizaron una media de siete acciones de activación para el empleo, lo cual ha resultado en una mejora de su empleabilidad, así como en una vinculación más estrecha con los servicios de búsqueda activa de empleo, ya que la frecuencia de su utilización se prolonga en el tiempo más allá del periodo de la intervención, muy por encima de los datos recogidos del grupo de control.

En segundo lugar, los participantes en ERSISI han tenido un mejor comportamiento en relación con el empleo, si bien este dato, se señaló, ha de tomarse con cautela dado que no resultará posible medir las consecuencias reales en el empleo hasta que haya transcurrido un periodo de tiempo más largo desde el final de la intervención. No obstante, la presencia de las personas beneficiarias de ERSISI en el mercado de trabajo durante los seis meses siguientes a la finalización de la intervención ha sido superior a la del grupo de control. En torno al $32 \%$ de las personas participantes obtuvieron un contrato laboral en el semestre posterior a participar en el programa. La evaluación revela también indicios de mayor calidad en el empleo (contratos de jornada completa) de las personas beneficiarias de ERSISI en comparación con el grupo de control.

\section{Prevención e inversión social: el auge de la intervención precoz con la infancia en situación de desventaja}

De acuerdo con el Pacto Vasco por las Familias y por la Infancia, aprobado en 2018 por todas las instituciones vascas, "en los últimos años se está articulando una nueva constelación de argumentos a favor de la inversión pública proactiva dirigida a la infancia. Estos nuevos discursos entienden que invertir en infancia supone invertir en el futuro de nuestra sociedad. En este nuevo paradigma de la política social, el gasto público en infancia ya no representa un coste social, sino el eje principal de una inversión social productiva, orientada hacia el futuro. Avalado por una ingente investigación social, este nuevo paradigma reclama intensificar los esfuerzos para combatir la pobreza infantil, apoyar a las familias en dificultades para equilibrar su dedicación al trabajo y a las responsabilidades familiares, o incentivar la participación en la educación preescolar de hijos de familias con bajos recursos culturales y educativos" (Gobierno Vasco, 2018: 9).

Este enfoque entronca con el paradigma de la inversión social, cuya principal característica es el cambio de énfasis desde unas políticas orientadas a la reparación hacia otras orientadas a la preparación, a partir de la consideración de las políticas familiares, educativas y de igualdad de género, entre otras, como un elemento clave para el desarrollo no solo social, sino también económico. Desde ese punto de partida, este enfoque pone su atención en servicios que permiten invertir en la infancia, generar las condiciones que permitan un cierto nivel de igualdad de oportunidades y de movilidad social, facilitar los procesos de emancipación y transición a la edad adulta, apoyar a las familias con hijos y facilitar el acceso de las mujeres al empleo remunerado.

También entronca con el creciente interés por la intervención precoz (la intervención durante los primeros mil días de vida) ${ }^{34}$ y la preocupación por las crecientes dificultades para la movilidad social. A partir de la idea de que la actual crisis económica, el incremento de las desigualdades y el cambio de modelo productivo reducen la igualdad de oportunidades y perjudican especialmente a aquellos niños y niñas que no han podido recibir de sus padres y madres una suficiente dotación de capital (económico, cultural o relacional), diversas instituciones vienen destacando la necesidad de desarrollar políticas educativas, culturales y de garantía de ingresos que permitan neutralizar esas diferencias y asegurar un nivel básico de igualdad de oportunidades para todas las personas, independientemente de cuál sea el patrimonio económico, cultural o educativo de sus familias de origen.

Cabe recordar también al respecto que la procedencia de contextos familiares vulnerables afecta de forma decisiva a las oportunidades vitales de niños y niñas. Un punto de partida desfavorable en la infancia se relaciona con un menor acceso a la formación y la cultura, un bajo rendimiento escolar, peores índices de salud física y mental y una mayor probabilidad de adoptar conductas de riesgo y comportamientos antisociales a lo largo de la vida (Assiego y Ubrich, 2015; Harvey, 2014; Allen, 2011; Waldfogel y Washbrook, 2011; Field, 2010). Las desigualdades

${ }^{34}$ El propio Pacto por las Familias y por la Infancia explica que son cada vez más numerosos y concluyentes los estudios que asocian los primeros años de vida y la intervención precoz con el potencial de desarrollo a lo largo de toda la vida, bajo un paradigma común que cabe englobar en el concepto genérico de los "años fundamentales" (foundation years), en el sentido de que se trata de la fase en la que se colocan los fundamentos de toda la trayectoria vital posterior. Efectivamente, sólidas investigaciones de ámbitos disciplinares dispares vinculan positivamente la inversión en la primera infancia con una mayor participación de las mujeres en el mercado laboral, unos mayores índices de fertilidad, una mejora en la igualdad de oportunidades entre niños y niñas de distinta procedencia socioeconómica y, por último, una mejor sintonía con las necesidades de la llamada "sociedad del conocimiento". En ese sentido, multitud de investigaciones apuntan a que el momento óptimo para una intervención productiva es cuando los niños y niñas son muy pequeños. Existe en ese sentido una amplia evidencia que apunta a que las intervenciones educativas resultan tanto más rentables o eficiente en costes cuanto antes se desarrollen. Las intervenciones más tardías pueden ser lógicamente efectivas, pero en general la forma más eficaz y eficiente en costes de ayudar a las familias consiste en intervenir en los primeros años de vida de sus hijos e hijas. 
generadas en la infancia, además, impactan a lo largo de todo el ciclo vital de las personas, dando lugar a una reproducción o transmisión intergeneracional de la pobreza y la exclusión social (Foessa, 2016; Unicef, 2014; Field, 2010).

Se han desarrollado por tanto con fuerza en los últimos años diversos programas compensatorios de atención a la infancia en situación de riesgo social (SIIS, 2017C). Estas políticas no solo contribuyen a promover la igualdad de oportunidades en edades tempranas, sino que existe una evidencia científica creciente de que tienen un retorno económico y social positivo. El principal objetivo de las políticas de refuerzo en la infancia es contribuir al desarrollo integral de los niños y niñas en situación de desventaja social. Desde el punto de vista de su contenido, las intervenciones se centran en los siguientes ámbitos:

- La provisión de servicios de atención temprana y detección precoz dirigidos a ofrecer apoyo suplementario a las familias desde el momento del nacimiento y durante los primeros años de vida del menor (de cero a deis años), una fase crítica del desarrollo que tiene un efecto de largo alcance en las capacidades cognitivas, emocionales y sociales de los niños y niñas en etapas posteriores de la infancia, la adolescencia y la edad adulta.

- La mejora de las habilidades parentales de los padres y madres para hacer frente a las distintas etapas de la crianza de sus hijos o hijas, especialmente, mediante la implementación de programas de parentalidad positiva y servicios de orientación o asesoría en situaciones de conflicto familiar.

- La promoción de la salud física y mental de los y las menores, a través de:

- Servicios y programas de salud maternoinfantil dirigidos a garantizar unas buenas condiciones de salud y bienestar de los menores y sus madres durante los primeros años de vida.

- Programas que garanticen el acceso a servicios (logopedia, psicomotricidad) y bienes (gafas, audífonos, etc.) relacionados con la salud de los menores que no están cubiertos por el sistema de salud pública.

- Promoción de hábitos de vida saludables en la familia en ámbitos como la alimentación, la higiene, la actividad física o el ejercicio.

- Programas dirigidos a promover el desarrollo de competencias sociales y emocionales de niños y niñas.

- La mejora del rendimiento escolar de los niños y niñas procedentes de entornos desfavorecidos mediante:

- Programas dirigidos a promover la participación y las competencias de padres y madres en el apoyo y acompañamiento a la educación de sus hijos e hijas.
- Programas de refuerzo, más allá del horario escolar, dirigidos a ofrecer apoyo a los niños y niñas que muestran dificultades de aprendizaje.

- Programas dirigidos a garantizar el acceso de los niños y niñas a material escolar y otros equipamientos necesarios para participar adecuadamente en el entorno de la educación formal, pero también para crear entornos de aprendizaje en sus respectivos hogares que contribuyan a su estimulación y desarrollo cognitivo.

- Favorecer el acceso de los niños y niñas a programas y actividades culturales, de ocio y tiempo libre:

- Mediante fórmulas subvencionadas de acceso a las actividades culturales, de ocio y tiempo libre para los y las menores en el marco de la oferta dirigida al conjunto de la población.

- Favoreciendo el acceso de las familias en situación de desventaja social a programas de actividades culturales, ocio y tiempo libre en familia.

- Mediante programas que ofrezcan actividades culturales, de ocio y tiempo libre para los y las menores procedentes de familias en situación de desventaja social los fines de semana y durante los periodos vacacionales.

- Tratar de que los programas incluyan también acciones que contribuyan a mejorar la situación de los padres y madres en aquellas áreas donde presenten una mayor vulnerabilidad (ámbito económico, problemas de salud mental, soledad, aislamiento y falta de redes de apoyo, baja formación, desconocimiento del idioma local o escasas habilidades personales o sociales).

Entre los diferentes programas que, de forma sucinta cabe destacar en esta línea, es necesario hacer referencia al Family-Nurse Partnership ${ }^{35}$ estadounidense, el Incredible Years británico $0^{36} \mathrm{o}$ el

${ }^{35}$ El programa Family-Nurse Partnership tiene como objetivo mejorar el bienestar de las madres jóvenes primerizas con bajos ingresos y sus hijos/as. Los objetivos de la intervención son: a) mejorar los hábitos de salud de la madre (consumo de tabaco, alcohol y otras drogas), el autocuidado y la realización de los controles prenatales necesarios durante el embarazo; b) optimizar el estado de salud y el desarrollo de los y las menores durante los dos primeros años de vida, capacitando a los padres en la provisión de un cuidado más responsable y competente; d) mejorar la situación económica de las familias a través de la planificación familiar, el acceso de los progenitores a formación y la promoción del acceso a un empleo estable. El programa se articula mediante visitas domiciliarias realizadas por un enfermero o enfermera. Estas visitas se extienden desde el periodo del embarazo hasta que el niño o niña cumple los dos años de edad. El profesional actúa como un profesional de referencia, de modo que, idealmente, debe mantenerse durante todo el tiempo que dura la intervención. Los enfermeros y enfermeras que participan en el programa reciben una formación específica de dos semanas antes de incorporarse. La frecuencia de las visitas es en un principio quincenal y se va espaciando a medida que avanza el programa. No obstante, la frecuencia debe ajustarse a las necesidades de cada familia, pudiendo llegar a realizarse visitas semanales en los casos en que sea necesario.

${ }^{36} \mathrm{El}$ programa Incredible Years tiene como objetivo mejorar las habilidades parentales para la crianza de los hijos e hijas, promoviendo una parentalidad positiva. Este programa de parentalidad positiva 
subprograma de refuerzo educativo del programa Prolnfancia de La Caixa ${ }^{37}$.

\section{Bonos de impacto social}

Numerosos estudios confirman que las inversiones públicas dirigidas a la prevención de problemas sociales y problemas de salud revierten en ahorro para el sector público. A pesar de ello, resulta difícil conseguir financiación pública para las iniciativas sociales de carácter preventivo. Este hecho se debe en parte a la crisis económica, que ha conllevado la implantación de políticas de austeridad acentuando los ya anteriormente existentes problemas de financiación de programas públicos. Unos presupuestos públicos cada vez más ajustados provocan, por otro lado, una necesidad emergente de justificar el gasto de las Administraciones Públicas mediante evaluaciones de resultados. En un intento de dar respuesta a estos retos surgieron en 2007 en el Reino Unido los primeros bonos de impacto social (BIS) del mundo. Estos bonos, también conocidos como contratos de pago por éxito o bonos con pago por resultado, constituyen un mecanismo de financiación novedoso que promueve la innovación social y la efectividad de los programas públicos. Se trata concretamente de una fórmula de financiación que consiste en el compromiso de inversores privados de invertir dinero en acciones de carácter social promovidas por las entidades públicas. La Administración Pública, por su parte, se compromete a reembolsar esta inversión si se comprueba el cumplimiento de los objetivos del programa en cuestión.

Como regla general, el establecimiento y la implantación de un bono de impacto social contempla los siguientes pasos:

se centra en fortalecer el vínculo entre los menores y sus progenitores, así como en mejorar las interacciones entre ambos. Uno de los objetivos principales es reducir los comportamientos punitivos por parte de los padres - que tienden a reforzar el mal comportamiento de los y las menores- y sustituirlos por respuestas que promuevan las habilidades sociales, emocionales y lingüísticas de los hijos e hijas. Además, en los programas orientados a los menores en edad preescolar o escolar el programa hace un fuerte hincapié en la estimulación de las habilidades cognitivas y lingüísticas de los y las menores, con el objetivo de mejorar su rendimiento académico.

37 El programa Prolnfancia de La Caixa (Riera y Longás, 2013) tiene como objetivo ofrecer actividades de refuerzo educativo a menores en situación de desventaja social que presentan dificultades de escolarización. Las actividades de refuerzo educativo que integran el programa tienen como objetivo desarrollar tres funciones, que en ocasiones pueden ser complementarias: prevención, reeducación y refuerzo permanente. El enfoque preventivo se centra en apoyar al alumnado con contextos familiares muy desestructurados, donde la concurrencia de numerosos indicadores de riesgo aconseja realizar las intervenciones de forma preventiva. Las actividades reeducativas, sin embargo, se dirigen a atender dificultades específicas a partir de un diagnóstico psicopedagógico afinado. El objetivo es llegar a compensar las dificultades del alumno o alumna (bloqueos en alguna materia, mecánica de determinados procedimientos de lectura, cálculo, etc.), momento en que cesa la intervención. Finalmente, las actividades de refuerzo permanente ofrecen apoyo continuado al alumnado que presenta dificultades manifiestas para seguir los aprendizajes o que está en riesgo evidente de fracaso escolar.
1. Una entidad pública identifica una necesidad social no cubierta.

2. Se selecciona una entidad sin ánimo de lucro para diseñar e implementar un programa innovador de carácter preventivo.

3. Inversores privados se comprometen a financiar el programa en cuestión.

4. Se diseña el programa estableciendo el periodo de tiempo durante el que se implementará el programa y definiendo los indicadores adecuados para evaluar sus efectos sociales.

5. El programa se lleva a cabo.

6. Una evaluación externa determina si el programa cumple con los objetivos acordados al inicio.

7. Si el programa cumple con los resultados esperados, la entidad pública promotora asume el gasto que incluye el coste del proyecto y un porcentaje adicional en forma de "tasa de retorno" por la inversión. En el caso de que el programa no haya alcanzado los resultados esperados, los inversores pierden el capital.

Este nuevo modelo de financiación presenta una serie de ventajas, entre las que destacan las siguientes:

- Optimización del uso de los presupuestos públicos gracias a la minimización de los gastos de funcionamiento directo (contratación de personal, por ejemplo).

- Transferencia de los riesgos del sector público a otros actores.

- Reducciones en el gasto social público sin disminuir por ello los presupuestos disponibles para la intervención social.

- Aumento de los presupuestos destinados a iniciativas de prevención social y atención temprana, contribuyendo de esta manera a llenar un vacío que existe en la prestación de servicios sociales.

- Adopción de iniciativas basadas en la innovación social.

- Impulso de evaluaciones de servicios que, a su vez, contribuyen a generar nuevo conocimiento sustentado en la evidencia, creando así una cultura de aprendizaje.

- Incentivo de programas de intervención basados en la evidencia que, a su vez, contribuye al desarrollo de un rendimiento óptimo de los servicios.

- Fomento de la diversidad entre los prestadores de servicios.

No obstante, los bonos de impacto social también han sido objeto de críticas, entre las que destacan algunas:

- Los BIS constituyen, al igual que otros tipos de bonos, un instrumento financiero de deuda. Sin embargo, a diferencia de otros bonos, no tienen 
un rendimiento garantizado, lo cual, desde el punto de vista de los inversores, convierte su uso en una especie de "juego".

- Los inversores se comprometen a aportar capital durante un periodo de tiempo limitado, lo cual puede convertir la prestación de servicios en algo puntual que depende de la situación coyuntural.

- La implantación de los BIS implica la introducción de un nuevo mecanismo de competencia de mercado. Como resultado de ello, entidades que son muy buenas en la prestación de servicios pero que no cuentan con la capacidad de adaptarse a cambios de manera rápida podrían verse marginadas.

- Existe, por otro lado, un riesgo de que las entidades involucradas pierdan de vista el objetivo principal de la iniciativa y se interesen únicamente por poder demostrar el cumplimiento de los objetivos.

- Otra crítica frecuente se refiere a la complejidad del modelo que, según la opinión de muchos, debería ser simplificado y estandarizado para agilizar la gestión de los bonos de impacto social.

Desde la puesta en marcha del primer proyecto piloto con bonos de impacto social, dirigido a financiar un programa de rehabilitación de personas reclusas, este modelo de financiación se ha extendido de manera rápida a escala internacional. De hecho, entre 2010 y 2016 se implantaron nada menos que 74 proyectos de bonos de impacto social en quince países diferentes.

Los bonos de impacto social se han utilizado para financiar programas dirigidos a diversos colectivos, entre ellos personas exreclusas, personas sin hogar, personas jóvenes sin empleo y sin estudios, y menores en situación de desamparo. Según estimaciones recientes, el capital total invertido globalmente mediante este nuevo modelo de financiación supera los 250 millones de euros. En los siete años que han pasado desde la implantación del primer bono de impacto social este nuevo instrumento de financiación ha evolucionado, pero probablemente es aún pronto para poder calificarlo como un "modelo consolidado". En realidad, en la actualidad, los bonos de impacto social no constituyen una única fórmula de financiación, sino más bien un conjunto de mecanismos de financiación con algunas características comunes y que se encuentran en vías de estandarización.

\section{2. ¿Qué funciona? La práctica basada en (o informada por) la evidencia}

Durante muchos años, debido a sus orígenes y a su trayectoria histórica, los servicios sociales se han identificado con la beneficencia y, en todo caso, con la atención a situaciones que requerían una respuesta urgente, de emergencia. En ese contexto, el mero hecho de intervenir - con un programa, una prestación económica, un alojamiento, etc.- se consideraba ya en general una aportación suficiente a la resolución del problema y a la calidad de vida de las personas atendidas. El contenido concreto de la intervención y, sobre todo, su capacidad para dar una respuesta eficaz a los problemas planteados se consideraba a menudo una cuestión secundaria, supeditada a la urgencia de la intervención.

La progresiva consolidación de los servicios sociales como un derecho social del conjunto de la ciudadanía, el énfasis en su capacidad preventiva y la paulatina equiparación con otros ámbitos de las políticas públicas - como la educación o la sanidadhan hecho sin embargo que prestemos en este ámbito cada vez una mayor atención a la calidad de las intervenciones y a la necesidad de demostrar su eficacia y su eficiencia. Se ha tendido así a incorporar -a veces de forma un tanto acrítica- planteamientos muy enraizados en las ciencias de la salud, como la práctica basada en la evidencia. En su aplicación al ámbito de los servicios sociales, la idea fundamental de la práctica basada en la evidencia se centra en que la intervención social se debe asentar de forma sistemática en un conocimiento contrastado de su efectividad, derivado a su vez de la utilización de métodos sólidos de investigación empírica.

La traslación de este movimiento a los procesos de intervención social resulta sin duda necesaria en la medida en que reivindica elementos razonables, aunque hasta ahora poco presentes en este campo, tales como:

- el carácter científico de la intervención social;

- la necesidad de no improvisar y de no guiarse solo por el sentido común, sino también por el contraste y la verificación de la intervención; y

- la necesidad de elevar, en definitiva, la intervención social a una fase más adulta mediante la selección rigurosa de las intervenciones más efectivas.

Desde esta filosofía, se entiende que los servicios deben evaluarse no ya solo desde la perspectiva de su actividad (indicadores de proceso relacionados con las coberturas alcanzadas, número de personas atendidas, gasto realizado, etc.), sino de los resultados que se obtienen para las personas usuarias en función de los objetivos concretos establecidos previamente para cada intervención. Este deber está relacionado con la buena práctica profesional y con el principio ético de no maleficencia, que establece que la principal obligación ética de los profesionales que trabajan con personas es no dañarlas a través de su actuación; aplicar intervenciones cuya efectividad se haya demostrado mediante investigaciones experimentales de carácter científico constituye una manera de dar cumplimiento a este imperativo ético de la buena práctica profesional.

El paradigma de la práctica basada en la evidencia aplicado a los servicios sociales se materializa 
-entre otras muchas experiencias, enfoques 0 herramientas- en dos grandes tendencias: el recurso a las revisiones sistemáticas, por una parte, y el impulso de las evaluaciones y los proyectos experimentales, por otra. En lo que se refiere a las revisiones de la evidencia científica, son cada vez más frecuentes las revisiones sistemáticas ${ }^{38} y$ metanálisis de la literatura que permitan identificar la evidencia respecto al resultado de las intervenciones y difundir las buenas prácticas. Aunque más orientada al ámbito de la salud, la Cochrane Library recoge numerosas revisiones sistemáticas de intervenciones de diversos tipos en el ámbito de la atención a las personas con dependencia, discapacidad, enfermedad mental o adicciones (Maayan et al., 2014) y son cada vez más numerosas las revisiones sistemáticas sobre intervenciones en ámbitos relacionados con los servicios sociales: por citar algunos ejemplos, salud mental y precariedad laboral (Llosa et al., 2018), prestaciones de vivienda para colectivos vulnerables (Esquerra et al., 2018), intervenciones no farmacológicas para la mejora de la calidad de vida de las personas cuidadoras de pacientes con enfermedad de Alzheimer (AmadorMartín y Guerra-Martí, 2017), intervenciones dirigidas a reducir las sujeciones físicas en personas mayores institucionalizadas (Briones y Rodríguez, 2017), prevención y control de virus transmitidos por la sangre en entornos penitenciarios (EDCPC, 2018),intervenciones para reducir el consumo excesivo de alcohol por parte de personas mayores (Kelly et al., 2018), efectividad de las medidas de reparto del empleo (SIIS, 2015) o coste-efectividad de los programas de prevención de drogodependencias (SIIS, 2013), entre otras.

En esa línea, resulta también especialmente interesante el despliegue de la red de What Works Centres de Reino Unido ${ }^{39}$ y Escocia ${ }^{40}$. Esos centros se han configurado en el Reino Unido como plataformas colaborativas - con participación de entidades públicas y privadas- para generar y difundir la evidencia disponible sobre las intervenciones más eficaces. Resultan particularmente interesantes en ese sentido el National Institute for Health and Care Excellence (NICE) ${ }^{41}$, el Centre for Ageing

${ }^{38}$ Las revisiones sistemáticas son investigaciones científicas en las que la unidad de análisis son los estudios originales primarios, a partir de los cuales se pretende contestar a una pregunta de investigación claramente formulada mediante un proceso sistemático y explícito. Por eso se las considera investigación secundaria ("investigación sobre lo investigado"). Por el contrario, a las revisiones que no siguen un proceso sistemático, denominadas "revisiones narrativas", no se las puede considerar un proceso formal de investigación, sino simplemente un formato de literatura científica basada sobre todo en opinión (Ferreira, Urrutia y Alonso-Coello, 2011). Son también cada vez más frecuentes las llamadas "revisiones exploratorias". Frente a las revisiones sistemáticas, los objetivos de estas revisiones exploratorias serían identificar el tipo de evidencia disponible en un ámbito determinado, clarificar los conceptos clave, examinar los enfoques metodológicos utilizados en un ámbito específico, sentar las bases para una posterior revisión sistemática o identificar las lagunas de conocimiento existentes en un ámbito determinado (Munn et al., 2018).

39 https://www.gov.uk/guidance/what-works-network/.

$4^{0} \mathrm{http}: / /$ whatworksscotland.ac.uk.

${ }^{41}$ https://www.nice.org.uk.
Better ${ }^{42}$, el What Works for Children's Social Care ${ }^{43} 0$ el Centre for Homelessness Impact ${ }^{44}$. También cabe hacer referencia al papel que en este ámbito juega la Alliance for Useful Evidence ${ }^{45}$, una iniciativa mixta para promocionar el uso inteligente de la evidencia científica en el ámbito de las políticas sociales.

También es cada vez más habitual, como se ha dicho antes, la realización de programas piloto de carácter experimental con carácter previo a la generalización de una intervención, utilizando en general enfoques experimentales o cuasi experimentales, preferentemente con ensayos controlados aleatorizados. Ensayos de ese tipo se han desarrollado en nuestro entorno más cercano para la evaluar el efecto de múltiples intervenciones. Uno de los ejemplos más recientes - pero en ningún caso el único- se refiere a la nueva generación de proyectos experimentales relacionados con la aplicación de la Renta Básica y que, como han puesto de manifiesto diversas revisiones, han partido de pilotos experimentales generalmente bien diseñados (Tena, 2018; Gibson et al., 2018). Por citar al menos un ejemplo reciente, cabe hacer referencia al proyecto B-MINCOME, desarrollado en Barcelona, para testar la aplicación de diversos modelos de rentas garantizadas en la ciudad.

De acuerdo con el primer informe de evaluación del proyecto, el proyecto piloto B-MINCOME, que combina una renta mínima garantizada y políticas sociales activas en zonas urbanas desfavorecidas de Barcelona, es un proyecto piloto de lucha contra la pobreza y la exclusión social enmarcado en el programa Urban Innovative Actions de la Unión Europea y promovido por la Dirección de Planificación e Innovación del Área de Derechos Sociales del Ayuntamiento de Barcelona. El proyecto B-MINCOME tiene una duración global de 36 meses que comprenden los 24 de intervención y de evaluación (de noviembre de 2017 a octubre de 2019) y un año previo de preparación del diseño experimental, de diagnóstico, de muestreo y de obtención de datos, iniciado en noviembre de 2016.

Como explica Laín (2019), durante el periodo de intervención, y siguiendo el modelo de los ya señalados estudios aleatorios con grupo de control, mil hogares aleatoriamente seleccionados de tres de los distritos más pobres de la ciudad han estado recibiendo una renta de entre 100 y 1.675 euros mensuales. La mitad de estos hogares también han participado en las cuatro políticas activas de inclusión sociolaboral que el proyecto ha puesto en marcha: una de formación y ocupación; una de fomento del emprendimiento en la economía social, solidaria y cooperativa; una de ayudas a la rehabilitación de pisos para alquilar habitaciones; y una de participación comunitaria. Cerca de 500

\footnotetext{
$4^{2}$ https://www.ageing-better.org.uk.

43 https://whatworks-csc.org.uk.

44 https://www.homelessnessimpact.org.

45 https://www.alliance 4 usefulevidence.org.
} 
hogares más están participando de forma pasiva, esto es, actúan como grupo de control con el cual comparar los resultados obtenidos en los 1.000 hogares pertenecientes a los distintos grupos de tratamiento. Lo que hace más interesante e innovador este proyecto es que en él se combinan cuatro modalidades de participación: la condicionada (las personas aleatoriamente asignadas a una política activa están obligadas a participar en ella), la no condicionada (la participación en las políticas no es obligatoria para seguir percibiendo la renta), la limitada (los ingresos adicionales que se puedan conseguir reducen la cantidad de la renta de forma proporcional) y la no limitada (en que estos ingresos adicionales no reducen la cantidad de renta a percibir) y que es la modalidad más similar al modelo de renta básica incondicional.

De acuerdo con este autor, en línea con los resultados obtenidos en experimentos similares, como el de Manitoba en la década de 1970 (Forget, 2011), el de Finlandia, (Kangas et al., 2019), el repentinamente cancelado de Ontario (Basic Income Canada Network, 2019) o los que están finalizando ahora en varias ciudades neerlandesas como Utrecht ${ }^{46}$, el informe publicado por el Ayuntamiento de Barcelona pone de manifiesto resultados cuantitativos positivos, por ejemplo, el incremento del $11 \%$ de media en el bienestar general o de 1,4 puntos porcentuales en el bienestar económico. También muestra una reducción de 8 puntos en el índice de privación material severa, y de hasta 18 puntos en la preocupación por no tener comida. Destaca también la reducción de 3 puntos de media en la necesidad de ingresar dinero por vías no laborales (por ejemplo, mediante el alquiler de habitaciones, una problemática especialmente acuciante en la ciudad de Barcelona) o la reducción de desarrollar enfermedades mentales y la mejora de la calidad del sueño, en 10 y 1 punto porcentuales de media respectivamente - unos resultados asociados a la reducción del estrés financiero que sufren estas familias-. Asimismo, la evaluación cualitativa y etnográfica del proyecto también aporta resultados positivos, como un aumento de cerca del $28 \%$ de la felicidad y de la satisfacción general con la vida, así como un incremento significativo de la vinculación y la participación vecinal y comunitaria.

Sin embargo, concluye Laín (2019), el informe no ha detectado cambios estadísticamente significativos ni en la inseguridad habitacional ni en la capacidad para afrontar gastos inesperados (aunque la cantidad de la transferencia monetaria no permite el ahorro, sino básicamente poder hacer frente a los gastos básicos habituales). Asimismo, tampoco se observan resultados significativos en la inserción laboral ni en la mayoría de dimensiones relacionadas con el empleo.

El paradigma de la práctica basada en la evidencia presenta en cualquier caso limitaciones de

46 https://www.uu.nl/en/news/what-works-researchers-fromutrecht-university-to-conduct-study-into-better-welfare-benefits. importancia, muy particularmente cuando se aplica en el ámbito de las políticas sociales ${ }^{47}$. Se ha cuestionado en ese sentido no solo la discutible definición del concepto de evidencia y la también discutible selección de los métodos para identificarla, sino también la dificultad para trasladar esa evidencia al ámbito de la decisión, la planificación y la regulación, así como al ámbito de la intervención directa (Boaz et al., 2019). Por ello, desde enfoques alternativos han surgido otras iniciativas basadas en la coproducción del conocimiento, como las plataformas de Research in Practice ${ }^{48}$ desarrolladas en el Reino Unido, que intentar promover una práctica informada por (y no basada en) la evidencia. La práctica informada por la evidencia, de acuerdo con esta organización, se refiere a una metodología particular utilizada en el diseño, provisión y evaluación de servicios de atención social. El enfoque informado por la evidencia vincula y relaciona la investigación académica con el conocimiento de las personas profesionales y las personas usuarias de los servicios. Este enfoque se relaciona con otras formas de coproducción de los servicios y cuestiona la evidencia generada únicamente desde presupuestos académicos o científicos.

\section{Elementos comunes}

Para terminar, se señalan a continuación los elementos comunes que con mayor o menor intensidad están presentes en todos los enfoques recogidos:

- Uno de los principales elementos de casi todas las experiencias descritas se relaciona con el protagonismo de la personas y con la idea de individualización de los servicios, entendida como promoción de la autonomía y la capacidad de elección de las personas usuarias.

- También se hace patente en muchas de las experiencias analizadas un cuestionamiento de la idea de condicionalidad, en gran medida vinculada a la idea de elección y autonomía personal que se relaciona con la idea de personalización.

- Se aprecia una apuesta clara por los sistemas mixtos y la colaboración público-privada, en

${ }^{47}$ Como señalan Stoker y Evans (2016), hay pruebas suficientes respecto a las limitaciones de la evidencia y sobre las dificultades para incorporar los resultados que se derivan de estos enfoques a los procesos de toma de decisiones y a la práctica profesional. De acuerdo con estos autores, desde el punto de vista de la generación de evidencia científica, la mejor estrategia se basa en una utilización pluralista de métodos de investigación y difusión de la evidencia. Junto a las revisiones sistemáticas y los ensayos aleatorizados, estos autores destacan la importancia de otras metodologías como los análisis cualitativos comparados, los enfoques narratológicos (storytelling) y los análisis visuales, así como las técnicas de inteligencia de datos (big data), los análisis de conglomerados o clústeres, las microsimulaciones, las metodologías de ciencia ciudadana, el análisis deliberativo de políticas y las herramientas para la coproducción y el codiseño de políticas y programas de intervención.

${ }^{48}$ https://www.ripfa.org.uk. 
ocasiones desde la perspectiva de lo común. Las ideas de partenariado, de reconstrucción de lo común y de colaboración público-privada vuelven a salir a la palestra. Si bien las experiencias analizadas no cuestionan la responsabilidad pública en la prestación de los servicios sociales, en muchos casos es patente una diversidad de agentes que va mucho más allá de lo institucional.

- Otro de los elementos fundamentales se relaciona con el refuerzo de lo comunitario - atender en la comunidad y atender por la comunidad-, lo que lleva aparejado un rechazo claro a los aspectos más institucionales de la intervención social. Junto con lo comunitario, también ganan fuerza otros conceptos, como la cocreación, la coparticipación o la coproducción.
- Es también evidente, en casi todas las experiencias analizadas, un énfasis claro en la prevención y en la intervención precoz

- El elemento más novedoso y en cierto modo más disruptivo se refiere en cualquier caso a la desprofesionalización que subyace a casi todos estos modelos. En ese sentido, la mayor parte de las experiencias recogidas plantean un cambio radical en el papel de los y las profesionales, desde la crítica a modelos de intervención que se consideran paternalistas. El saber técnico, profesional o experto es sustituido por el saber de la persona usuaria, o de la comunidad, y las personas profesionales se ven obligadas a situarse en un nuevo plano en la relación con las personas atendidas. 
AGENCIA DE LOS DERECHOS FUNDAMENTALES DE LA UNIÓN EUROPEA (2018): From Institutions to Community Living for Persons with Disabilities: Perspectives from the Ground, serie Equality, Viena, Agencia de los Derechos Fundamentales de la Unión Europea 〈https://www.siis.net/es/ buscar/Record/524250>.

AMADOR-MARTíN, B. y GUERRA-MARTíN, D. (2017): "Eficacia de las intervenciones no farmacológicas en la calidad de vida de las personas cuidadoras de pacientes con enfermedad de Alzheimer", Gaceta Sanitaria, vol. 31, no 2, págs. 154160, «https://www.siis.net/es/buscar/ Record/523963).

ARRIETA, F. et al. (2018): "La comunidad al rescate: algunas reflexiones sobre las políticas estatales de activación comunitaria en Europa", Zerbitzuan, $\mathrm{n} 065$, págs. 5-18, <https://doi. org/10.5569/1134-7147.65.01>.

ASSIEGO, V. y UBRICH, T. (2015): Iluminando el futuro. Invertir en educación es luchar contra la pobreza infantil, Madrid, Save The Children España.

AUBRY, T. et al. (2015): “One-year outcomes of a randomized controlled trial of Housing First with ACT in five Canadian cities", Psychiatric Services, vol. 66, no 5 , págs. 463-469, 〈https://doi.org/10.1176/ appi.ps.201400167>.

AYALA, L. y PANIAGUA, M. (2019): “Los complementos salariales y la garantía de ingresos: posibilidades y límites", en Sevilla, J. (coord. y dir.), Reforzar el bienestar social: del ingreso mínimo a la renta básica, Barcelona, Observatorio Social de La Caixa, págs. 132-151, 〈https://www.siis.net/es/buscar/ Record/544489>.
AYUNTAMIENTO DE BARCELONA (2017): Servei d'Ajuda a Domicili $(S A D)$. Projectes pilots $S A D$ : noves formes de provisió. Roda de premsa, Barcelona, Ayuntamiento de Barcelona, <http:// ajuntament.barcelona.cat/premsa/wp-content/ uploads/2017/11/Presentaci\%C3\%B3-PilotSAD-Roda-29.11.2017def.pdf $>$.

BASIC INCOME CANADA NETWORK (2019): Signposts to Success: Report of a BICN Survey of Ontario Basic Income Recipients, Basic Income Canada Network, <https://assets.nationbuilder. com/bicn/pages/42/attachments/ original/1551664357/BICN_-_Signposts_to_ Success.pdf〉.

BENEDICTO, Z. (2013): “La prestación económica de asistencia personal en el territorio histórico de Gipuzkoa", Zerbitzuan, noํ5, págs. 67-84, 〈https://doi.org/10.5569/1134-7147.54.04〉.

BERNARD, R.; CENJOR, V. y YUNCAL, R. (2016): “El modelo Housing First en España: resultados a los 12 meses del programa", Barcelona Societat, n20, págs. 1-14, 〈https://ajuntament.barcelona. cat/dretssocials/sites/default/files/revistacastellano/11-el-modelo-housing-first-enespana-resultados-a-los-12-meses.pdf〉.

BLANCO, J. et al. (coords.) (2015): Modelo Inclúe. La apuesta por una atención de calidad en el ámbito de la inclusión social, Vigo, Grupo Emaús Fundación Social, 〈https://www.siis.net/es/buscar/ Record $/ 510625 />$.

BOAZ, A. et al. (eds.) (2019): What Works Now? Evidenceinformed Policy and Practice, Bristol, Policy Press, <https://www.siis.net/es/buscar/ Record/545233'.

BOUGET, D. et al. (2015): Integrated Support for the Longterm Unemployed. A Study of National Policies, 
Bruselas, Comisión Europea, 〈https://www.siis. net/es/buscar/Record/505914>.

BRADSHAW, S.A. et al. (2012): "Living well in care homes: A systematic review of qualitative studies", Age and Ageing, vol. 41, n- 4, págs. 429440, 〈https://www.siis.net/es/buscar/ Record/187181>

BRETHERTON, J. y PLEACE, N., (2015): Housing First in England. An Evaluation of Nine Services. York, Centre for Housing Policy, 〈https://www.siis. net/es/buscar/Record/195855>.

BRIONES, M.Á. y RODRÍGUEZ, B. (2017): “Efectividad de las intervenciones dirigidas a reducir las sujeciones físicas en personas mayores de 65 años institucionalizadas: una revisión sistemática”, Revista Española de Geriatría y Gerontología, vol. 52, no 2, 2017, págs. 93-101, <https://www.siis.net/es/buscar/ Record/525813>.

BUSCH-GEERTSEMA, V. (2013): Housing First Europe. Final Report and Local Evaluation Reports for Amsterdam, Budapest, Copenhagen, Glasgow and Lisbon, Bruselas, Comisión Europea, 〈http://www.habitat.hu/files/ FinalReportHousingFirstEurope.pdf $>$.

CADENA SER (2016): “Bizkaia y Gipuzkoa se apuntan al 'Housing First' para las personas sin hogar", La Ventana Euskadi, 8 de septiembre, <https:// cadenaser.com/emisora/2016/09/08/radio_ bilbao/1473313861_620898.html>.

CENTRO EUROPEO PARA LA PREVENCIÓN Y EL CONTROL DE LAS ENFERMEDADES (2018): Systematic Review on the Prevention and Control of Blood-borne Viruses in Prison Settings, Serie ECDC Technical Report, Estocolmo, Centro Europeo para la Prevención y el Control de las Enfermedades, 〈https://www.siis.net/es/ buscar/Record/545111>.

CHAUDHURY, H. y COOKE, H. (2014): “Design matters in dementia care: The role of the physical environment in dementia care settings", en Excellence in Dementia Care, $2^{\mathrm{a}}$ ed., Bershire, Open University Press, págs. 144-158, <https:// www.siis.net/es/buscar/Record/520938>.

CHOWDHURY, M. y BENSON, B.A. (2011):

"Deinstitutionalization and quality of life of individuals with intellectual disability: A review of the international literature", Journal of Policy and Practice in Intellectual Disabilities, vol. 8 , no ${ }^{4}$, págs. 256-265, <https://www.siis.net/es/ buscar/Record/184451>.

COFIÑO, R. et al. (2016): “Promoción de la salud basada en activos: ¿cómo trabajar con esta perspectiva en intervenciones locales? Informe SESPAS 2016", Gaceta Sanitaria, vol. 30, S1, 2016, págs. 93-98, <http://www.gacetasanitaria.org/ es-promocion-salud-basada-activos-comoarticulo-S021391111630125X).

DA ROIT, B. y LE BIHAN, B. (2019): “Cash for long term care: Policy debates, visions, and designs on the move", Social Policy and Administration, vol. 53, no 4 , págs. 519-536, <https://www.siis.net/ es/buscar/Record/543338>.

DE LA CAL, M.L (2014): “La pobreza laboral”, Boletín del Centro de Documentación Hegoa, nํㅜ 40, 〈http://boletin.hegoa.ehu.es/mail/33〉.
DÍAZ-VEIGA, P. et al. (2014): "Efectos del Modelo de Atención Centrado en la Persona en la calidad de vida de personas con deterioro cognitivo de centros gerontológicos", Revista Española de Geriatría y Gerontología, vol. 49, no 6, págs. 266-271, <https://www.siis.net/es/buscar/ Record/503563>.

DÍAZ-VEIGA, P. et al. (2016): “ ¿Estamos mejorando la atención? Efectos de intervenciones relativas al Modelo de Atención Centrado en la Persona en un grupo residencial", Zerbitzuan, $\mathrm{n}-61$, págs. 53-63, 〈https://doi.org/10.5569/11347147.61.04).

DIRECCIÓN GENERAL DE EMPLEO, ASUNTOS SOCIALES E IGUALDAD DE OPORTUNIDADES y COMISIÓN EUROPEA (2011): “Informe del grupo de expertos ad hoc sobre la transición de la asistencia institucional a la de base comunitaria", Zerbitzuan, n-0 49, págs. 147-160, 〈https://doi.org/10.5569/1134-7147.49.12〉.

DRENNAN, V.M. et al. (2018): “Tackling the workforce crisis in district nursing: Can the Dutch Buurtzorg model offer a solution and a better patient experience? A mixed methods case study", BMJ Journals, vol. 8, e021931, págs. 1-7, 〈https:// bmjopen.bmj.com/content/8/6/e021931).

ESQUERRA, Y. et al. (2018): Revisió sistemàtica de literatura sobre "Què funciona en ajuts a l'habitatge per a col-lectius de persones vulnerables", Barcelona, Institut Català d'Avaluació de Politiques Públiques, 〈https://www.siis.net/ es/buscar/Record/537281>.

FERNÁNDEZ, G. (coord.) (2015): Hacia un sistema más inclusivo de garantía de rentas, Fundación Foessa.

FERRARINI, T.; NELSON, K. y HÖÖG, H. (2012): The Fiscalization of Child Benefits in OECD Countries, serie Gini Discussion Paper, Ámsterdam, Growing Inequalities' Impacts, <https://www.siis.net/es/buscar/ Record/280014>.

FERREIRA, I.; URRUTIA, G. y ALONSO-COELLO, P. (2011): "Revisiones Sistemáticas y Metaanálisis: Bases Conceptuales e Interpretación", Revista Española de Cardiología, vol. 64, no 8, págs. 688-696, 〈https://doi.org/10.1016/j. recesp.2011.03.029>.

FIELD, F. (2010): The Foundation Years: Preventing Poor Children Becoming Poor Adults. The Report of the Independent Review on Poverty and Life Chances, Londres, Cabinet Office.

FORGET, E.L. (2011): “The town with no poverty: The health effects of a Canadian guaranteed annual income field experiment", Canadian Public Policy, vol. 37, nํㅜ 3, págs. 283-305, 〈https:// www.siis.net/es/buscar/Record/185038>.

FORTEA, C. y HERRUZ, L. (2017): “Primer la Llar: aplicación del modelo Housing First en la ciudad de Barcelona. Primeras reflexiones", Zerbitzuan, no 64, págs. 239-253, 〈https://doi. org/10.5569/1134-7147.64.17>.

GIBSON, M. et al. (2018): Universal Basic Income. A Scoping Review of Evidence on Impacts and Study Characteristics, Edimburgo, What Works Scotland, 〈https://www.siis.net/es/buscar/ Record/542288>. 
GOBIERNO DE ESPAÑA (2015): Estrategia Nacional Integral para Personas Sin Hogar 2015-2020, Madrid, Gobierno de España.

GOBIERNO DE NAVARRA (2019): “Orden Foral 224/2019, de 31 de mayo, del consejero de Derechos Sociales, por la que se regula la prestación económica para asistencia personal de las personas que tengan reconocida una situación de dependencia y/o discapacidad", Boletín Oficial de Navarra, n- 130, 5 de julio, 〈http://www.lexnavarra.navarra.es/detalle. asp? $r=51747$.

GOBIERNO VASCO (2018): Pacto Vasco por las Familias y la Infancia, Vitoria-Gasteiz, Eusko JaurlaritzaGobierno Vasco, <https://www.euskadi.eus/ contenidos/informacion/pactovascofamilias/ es_def/adjuntos/pactovasco.pdf .

GOMÀ, R. (2019): Derechos sociales y derecho a la ciudad. Municipalismo, bienestar de proximidad y agenda urbana. VIII Informe sobre exclusión y desarrollo social en España, serie Documento de Trabajo, no 6.6, Madrid, Fundación Foessa; Cáritas Española Editores, 〈https://www.siis. net/es/buscar/Record/543421>.

HARVEY, B. (2014): The Case for Prevention and Early Intervention. Promoting Positive Outcomes for Children, Families and Community. Dublín, Prevention \& Early Intervention Network.

HOUSING FIRST BELGIUM (2014): Mise en Place de l'Experimentation Housing First in Belgium, Bruselas, Housing First Belgium, 〈https://www. siis.net/es/buscar/Record/505001〉.

HUISMAN, E.R.C.M. et al. (2012): “Healing environment: A review of the impact of physical environmental factors on users", Building and Environment, vol. 58, págs. 70-80, 〈https://www.siis.net/es/ buscar/Record/520890>.

KENWORTHY, L. (2015): Do Employment-conditional Earnings Subsidies Work?, Amberes, Herman Deleeck Centre for Social Policy, <https://www.siis.net/ es/buscar/Record/508033'.

JOHNSEN, S. (2013): Turning Point Scotland's Housing First Project Evaluation. Final Report, Edimburgo, Institute for Housing, Urban and Real Estate Research, 〈https://pureapps2.hw.ac.uk/portal/ files/5945730/TPS_Housing_First_Final_ Report.pdf〉.

JOHNSEN, S. y TEIXEIRA, L. (2010): Staircases, Elevators and Cycles of Change. 'Housing First' and Other Housing Models for Homeless People with Complex Support Needs, Londres, Crisis, 〈https://www.siis.net/es/buscar/ Record/177472>.

JOSEPH, A. et al. (2016): “Impact of the physical environment of Residential Health, Care, and Support Facilities (RHCSF) on staff and residents. A systematic review of the literature", Environment and Behavior, vol. 48, no 10, págs. 1.203-1.241, 〈https://www.siis.net/ es/buscar/Record/520888>.

KANGAS, O. et al. (eds.) (2019): The Basic Income Experiment 2017-2018 in Finland. Preliminary Results, Helsinki, Ministry of Social Affairs and Health, 〈http://urn.fi/URN:ISBN:978-952-00-4035-2〉.

KELLY, S. et al. (2018): “Interventions to prevent and reduce excessive alcohol consumption in older people: A systematic review and metaanalysis", Age and Ageing, vol. 47, nº 2, págs. 175-184, 〈https://www.siis.net/es/buscar/ Record/536923>.

LAÍN, B. (2019): “El proyecto piloto B-MINCOME de Barcelona: experimentos, resultados y ¿mercado laboral?", Sin Permiso, 19 de septiembre, 〈http://www.sinpermiso.info/ textos/el-proyecto-piloto-b-mincome-debarcelona-experimentos-resultados-y-mercadolaborals.

LLOBET, M. y AGUILAR HENDRICKSÓN, M. (2016): “El Housing First. El derecho a la vivienda de los más vulnerables", Barcelona Societat, n을, págs. 1-14, «https://ajuntament.barcelona. cat/dretssocials/sites/default/files/revistacastellano/o6-housing-first-el-derecho-a-lavivienda-de-los-mas-vulnerables.pdf〉.

LLOSA, J.A. et al. (2018): “Job insecurity and mental health: A meta-analytical review of the consequences of precarious work in clinical disorders", Anales de Psicología, vol. 34, nº 2, págs. 211-223, <https://www.siis.net/es/buscar/ Record/542382>.

MAAYAN, N.; SOARES-WEISER, K. y LEE, H. (2014): “Respite care for people with dementia and their carers", Cochrane Database of Systematic Reviews, no 1, art. CD004396 <https://doi. org/10.1002/14651858.CDoo4396.pub3>.

MANSELL, J. et al. (2011): “Desinstitucionalización y vida en la comunidad. Declaración del Grupo de Investigación sobre Política y Práctica Comparativas, de la Asociación Internacional para el Estudio Científico de las Discapacidades Intelectuales (IASSID)", Zerbitzuan, no 0 49, págs. 137-146, 〈https://doi.org/10.5569/11347147.49.11>.

MARTÍNEZ, T. et al. (2014): La atención centrada en la persona. ¿En qué consiste este modelo de atención? / Pertsonarengan oinarritutako arreta. Zertan datza arreta-eredu hau?, serie Modelo de Atención Centrada en la Persona. Cuadernos Prácticos, no 1, Eusko JaurlaritzaGobierno Vasco, Fundación Matia <https:// www.siis.net/es/buscar/Record/197992>.

MARTÍNEZ RODRÍGUEZ, T. (2016): La atención centrada en la persona en los servicios gerontológicos, serie Estudios de la Fundación, nํㅜ 3, Madrid, Fundación Pilares, <https://www.siis.net/es/ buscar/Record/511365〉

MATULIĈ, M.V.; CABRE, C. y GARCIA GISPERT, A. (2016): "La atención a las personas sin hogar en la ciudad de Barcelona: una mirada histórica y de futuro", Barcelona Societat, $\mathrm{n}-20$ 20, 2016, págs. 1-17, <https://ajuntament.barcelona. cat/dretssocials/sites/default/files/revistacastellano/og-la-atencion-a-las-personas-sinhogar-en-la-ciudad-de-barcelona.pdf〉.

MCCABE, J.T. y POPP, E. (2016): “American exceptionalism revisited: tax relief, poverty reduction, and the politics of child tax credits", Sociological Science, vol. 3, págs. 540-567, 〈https://www. siis.net/es/buscar/Record/513659>.

MCQUAID, R.W. et al. (2007): Best Practice in Inter-agency Co-operation on Employability. Edimburgo, Employment Research Institute, Napier 
University, <https://www.researchgate.net/ publication/238767915_Best_practice_in_interagency_cooperation_on_employabilitys.

MILLER, S.C. et al. (2016): "Studying nursing home innovation: the Green House model of nursing home care", Health Services Research, vol. 51, supl. S1, págs. 335-343, 〈https://www.siis.net/ es/buscar/Record/519419>.

MINAS, R. (2014): “One stop shops: Increasing employability and overcoming welfare state fragmentation?", International Journal of Social Welfare, $\mathrm{n}$-23, S40-S53. <https://doi. org/10.1111/ijsw.12090〉.

MOGOLLÓN, I. y FERNÁNDEZ, A. (2016): Arquitecturas del cuidado. Viviendas colaborativas para personas mayores. Un acercamiento al contexto vasco y las realidades europeas, Vitoria-Gasteiz, Emakunde, 〈https://www.siis.net/es/buscar/ Record/514290>.

MORGAN, A. y HERNÁN, M. (2013): "Promoción de la salud y del bienestar a través del modelo de activos", Revista Española de Sanidad Penitenciaria, vol.15, nํㅜ 3, págs. 78-86.

MUNN, Z. et al. (2018): "Systematic review or scoping review? Guidance for authors when choosing between a systematic or scoping review approach", BMC Medical Research Methodology, no 18, art. 143, 〈https://doi. org/10.1186/s12874-018-0611-x>.

OBSERVATORIO DE LA REALIDAD SOCIAL (2018): Informe de evaluación de la aplicación de estímulos al empleo durante el primer año de vigencia de la Ley Foral 15/2016, de 11 de noviembre, por la que se regulan los derechos a la Inclusión Social y a la Renta Garantizada, Pamplona, Departamento de Derechos Sociales del Gobierno de Navarra, 〈https://www.siis.net/ es/buscar/Record/543041>.

PAULY, B. et al. (2013): "Housing and harm reduction: What is the role of harm reduction in addressing homelessness?", International Journal of Drug Policy, vol. 24, no 4, págs. 284-290, 〈https:// www.siis.net/es/buscar/Record/193831>.

PLEACE, N. y BRETHERTON, J. (2013): “The case for housing first in the European Union: A critical evaluation of concerns about effectiveness", European Journal of Homelessness, vol. 7, $\mathrm{n}$-2 2, págs. 21-41, 〈https://www.siis.net/es/buscar/ Record/195855>.

PLEACE, N. y QUILGARS, D. (2013): Improving Health and Social Integration through Housing First. A Review, York, Centre for Housing Policy, Bruselas, European Observatory on Homelessness, <https://www.siis.net/es/ documentacion/catalogo/Record/196149'.

QUILGARS, D. y PLEACE, N. (2016): "Housing First and social integration: A realistic aim?", Social Inclusion, vol. 4, n- ${ }^{\circ}$, p. 5-15, 〈https://www.siis.net/es/ documentacion/catalogo/Record/518127>.

RANCI, C. et al. (2019): “Coverage versus generosity: Comparing eligibility and need assessment in six cash for care programmes", Social Policy and Administration, vol. 53, nำ 4, págs. 551-566, <https://www.siis.net/es/buscar/ Record/543340>.
RIERA, J. y LONGÁS, J. (coords.) (2013): Programa CaixaProinfancia. Modelo de promoción y desarrollo integral de la infancia en situación de pobreza y vulnerabilidad social, $2^{\underline{a}}$ ed., Barcelona, Obra Social La Caixa, 〈https://www. siis.net/es/buscar/Record/181630>.

SANCHO CASTIELLO, M. y DÍAZ VEIGA, J. (2014):

"Aplicaciones prácticas del modelo de atención centrado en las personas en ámbitos residenciales. El Proyecto Etxe Ondoan", Actas de la Dependencia, $\mathrm{n}$ - 11, págs. 1-21, 〈https:// www.siis.net/es/buscar/Record/502327>.

SIIS CENTRO DE DOCUMENTACIÓN Y ESTUDIOS (2011): Prestaciones económicas y otras fórmulas de asignación económica individual en los sistemas de atención a la dependencia. Panorama comparativo internacional, Donostia-San Sebastián, Diputación Foral de Gipuzkoa, 〈https://www.siis.net/es/buscar/ Record/175166>.

- (2013): Revisión sistemática de evaluaciones económicas relativas a los programas de prevención del consumo de drogas, Madrid, Ministerio de Sanidad, Servicios Sociales e Igualdad, <https://www.siis.net/es/buscar/ Record/196720>.

- (2015): Revisión sistemática de la efectividad de las medidas de reparto de empleo, DonostiaSan Sebastián, Diputación Foral de Gipuzkoa, «https://www.siis.net/es/buscar/ Record/510376/>.

- (2016): Revisión de tendencias, innovaciones y buenas prácticas de inclusión sociolaboral, Pamplona, Observatorio de la Realidad Social, Gobierno de Navarra, 〈http:// www.navarra.es/NR/rdonlyres/ECFBDA6E7CD1-42EF-9919-A70C1DBEDD9E/359260/ Buenaspracticasdeinclusionsociolaboral.pdf $>$.

- (2017a): Activación comunitaria y solidaridad vecinal. Tendencias y buenas prácticas $=$ Aktibazio komunitarioa eta auzo-elkartasuna. Joerak eta jardunbide egokiak, Donostia-San Sebastián, Diputación Foral de Gipuzkoa, 〈https://www. siis.net/es/buscar/Record/532562>.

- (2017b): IV Plan Vasco de Inclusión Activa 2017-2021. Informe de diagnóstico, Vitoria-Gasteiz, Eusko Jaurlaritza-Gobierno Vasco, 〈http://www. euskadi.eus/contenidos/informacion/6199/ es_2284/adjuntos/o2 INFORME DE DIAGNOSTICO.pdf〉.

- (2017c): "Tendencias y buenas prácticas en la atención a la infancia en situación de riesgo social”, Zerbitzuan, no 63, págs. 89-102, 〈https://www. siis.net/es/buscar/Record/532562>.

STOKER, G. y EVANS, M. (eds.) (2016): Evidence-based Policy Making in the Social Sciences. Methods that Matter, Bristol, Policy Press, 〈https://www.siis. net/es/buscar/Record/517112〉.

TATLOW-GOLDEN, M. et al. (2014): Living Arrangement Options for People with Intellectual Disability: A Scoping Review. Dublín, School of Social Work and Social Policy, Trinity College Dublin, <https://www.siis.net/es/buscar/ Record/524250>.

TENA, A. (2018): "La Renta Básica Universal basada en la evidencia”, Política y Sociedad, vol. 55, no 
3, págs. 851-871, <https://www.siis.net/es/ buscar/Record/543360>.

TORRENS, L. (2018): Envejecimiento y mejora de la gestión pública: el caso de Barcelona y las supermanzanas sociales, serie Nota 2/2018. Barcelona, Transjus, Universitat de Barcelona, 〈http://diposit.ub.edu/dspace/ handle/2445/123257>.

VAN BERKEL, R. y BORGHI, V. (2008): “The governance of activation", Social Policy and Society, vol. 7, $\mathrm{n}^{-}$ 3, págs. 393-402, 〈https://www.siis.net/es/ buscar/Record/178100〉.

VANDENBROUCKE, F. et al. (2010): European Consensus Conference on Homelessness (9-10 December 2010, Brussels): Policy Recommendations of the Jury, Bruselas, Federación Europea de Organizaciones Estatales que Trabajan con las Personas sin Hogar, 〈https://www.siis.net/es/ buscar/Record/178767〉.

ZALAKAIN, J. (2014): "El papel de los sistemas de garantía de ingresos en el abordaje de la pobreza en el empleo: la experiencia del País Vasco", Lan Harremanak, no 31, págs. 36-62, 〈https://www. siis.net/es/buscar/Record/505552>.

- (2017): "Sistemas de bienestar y sociedad inclusiva: de la inclusión activa a la activación inclusiva",
Documentación Social, no 186, págs. 173189, 〈https://www.siis.net/es/buscar/ Record/534424>.

- (2019): "La fiscalización de las políticas sociales: funcionamiento e impacto de las deducciones fiscales reembolsables", Zerbitzuan, n- 68, págs. 111-141, 〈https://www.siis.net/es/ buscar/Record/543120>.

ZIMMERMAN, S. et al. (2013): "Systematic review: Effective characteristics of nursing homes and other residential long-term care settings for people with dementia", Journal of the American Geriatrics Society, vol. 61, no 8, págs. 1.3991.409, 〈https://www.siis.net/es/buscar/ Record/520964>.

- (2016): “New evidence on the Green House model of nursing home care: Synthesis of findings and implications for policy, practice, and research", Health Services Research, vol. 51, supl. S1, págs. 475-496, 〈https://www.siis.net/es/ buscar/Record/519325>.

ZUÑIGA, M. et al. (2019): "An analysis of the role of communities in care systems co-created with older people", Public Management Review, 8 de agosto, 〈https://www.siis.net/es/buscar/ Record/543833>. 